\title{
OPEN Peptide backbone modifications of amyloid $\beta(1-40)$ impact fibrillation behavior and neuronal toxicity
}

\author{
Benedikt Schwarze ${ }^{1}$, Alexander Korn ${ }^{1}$, Corinna Höfling ${ }^{2}$, Ulrike Zeitschel ${ }^{2}$, Martin Krueger ${ }^{3}$, \\ Steffen Roßner ${ }^{2}$ \& Daniel Huster $1{ }^{1}{ }^{\circledR}$
}

Fibril formation of amyloid $\beta$ (A $\beta$ ) peptides is one of the key molecular events connected to Alzheimer's disease. The pathway of formation and mechanism of action of $A \beta$ aggregates in biological systems is still object of very active research. To this end, systematic modifications of the $\mathrm{Phe}_{19}-\mathrm{LeU}_{34}$ hydrophobic contact, which has been reported in almost all structural studies of $A \beta_{40}$ fibrils, helps understanding $A \beta$ folding pathways and the underlying free energy landscape of the amyloid formation process. In our approach, a series of $A \beta_{40}$ peptide variants with two types of backbone modifications, namely incorporation of $(i)$ a methylene or an ethylene spacer group and (ii) a $\mathrm{N}$-methylation at the amide functional group, of the amino acids at positions 19 or 34 was applied. These mutations are expected to challenge the inter- $\beta$-strand side chain contacts as well as intermolecular backbone $\beta$-sheet hydrogen bridges. Using a multitude of biophysical methods, it is shown that these backbone modifications lead, in most of the cases, to alterations in the fibril formation kinetics, a higher local structural heterogeneity, and a somewhat modified fibril morphology without generally impairing the fibril formation capacity of the peptides. The toxicological profile found for the variants depend on the type and extent of the modification.

Alzheimer's disease (AD), being one of over 40 maladies caused by protein or peptide aggregation and misfolding, is a progressive and multifactorial disease leading to age-related changes in the brain. The etiology of AD is complex and influenced by genetic, environmental, and/or lifestyle factors ${ }^{1}$. In spite of intense research efforts invested into different aspects of this devastating form of dementia, AD is currently still incurable ${ }^{2}$. Progress in developing therapeutic treatment options is, among others, hampered by the long progression of the disease without any clinical symptoms, while moderate to severe levels of amyloid aggregates and neurofibrillary tangles in the brain result in the loss of neurons, disturbance of neuronal connectivity and in brain atrophy. The key molecular events underlying $\mathrm{AD}$ are fibril formation of amyloid $\beta(\mathrm{A} \beta)$ peptides and posttranslational modifications of the tau protein ${ }^{3,4}$.

However, amyloid fibril formation does not follow only a single pathway, but occurs through several routes in the energy landscape $e^{5,6}$. Intermediates that are formed on the way include soluble oligomers, to which strong neurotoxicity is ascribed via different molecular mechanisms such as membrane disruption, receptor-binding followed by activation of signaling pathways or glutamatergic neuronal hyperactivation ${ }^{7-9}$.

Details of $A \beta$ fibril formation have been intensively investigated in the last two decades predominantly using solid state NMR and cryo-EM approaches in combination with molecular modeling, Structural models of the transient $A \beta$ oligomers/protofibrils ${ }^{10-12}$ and structures of $A \beta$ fibrils ${ }^{13-17}$ have been determined extensively.

What remains highly enigmatic in the field of protein misfolding in general is the observation that peptides and proteins of no or of very diverse three-dimensional structure can form amyloids, in which the cross- $\beta$ structure is the only common conformational motif ${ }^{18,19}$. This suggests that very general physical interactions cause these peptides or proteins to aggregate and form fibrils. To investigate the contributions of specific physical interactions systematically, targeted perturbations induced by individual mutations in the A $\beta$ sequence represent a useful strategy $\mathrm{y}^{20-23}$. Each amino acid carries specific properties such that exchange of a given residue introduces a new physical force and the response of the system to such a perturbation can be analyzed in detail. Such

${ }^{1}$ Institute for Medical Physics and Biophysics, Leipzig University, Härtelstr. 16/18, 04107 Leipzig, Germany. ${ }^{2}$ Paul Flechsig Institute for Brain Research, Leipzig University, Liebigstr. 19, 04103 Leipzig, Germany. ${ }^{3}$ Institute of Anatomy, Leipzig University, Liebigstr. 13, 04103 Leipzig, Germany. ${ }^{\circledR}$ email: daniel.huster@medizin.uni-leipzig.de 


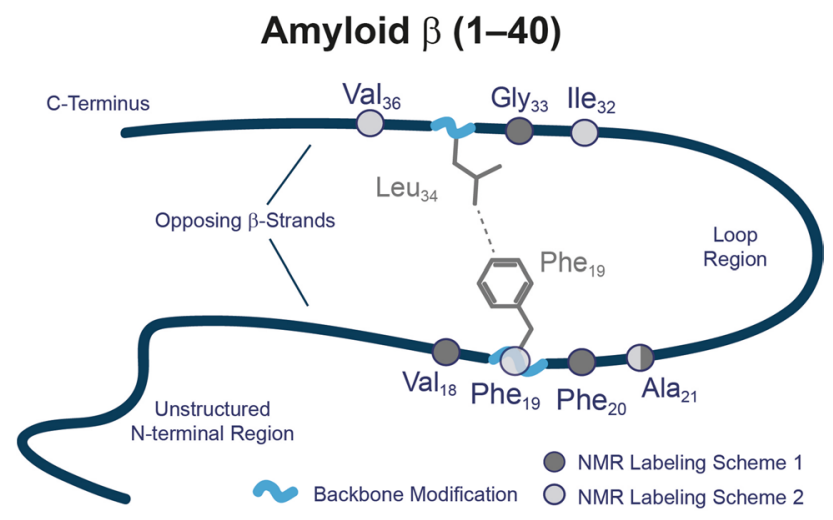

Figure 1. Schematic depiction of the $\mathrm{A} \beta_{40}$ structure visualizing the backbone modifications (light blue waves) introduced and the NMR labeling schemes applied. From the N-terminus, the peptide fibrils feature an unstructured $\mathrm{N}$-terminus continue with $\beta$-strand 1 which ends at the beginning of the loop region, followed by $\beta$-strand 2 and the C-terminus. Both $\beta$-strands oppose each other with the side chains of the respective amino acids interacting in a steric-zipper motif. We targeted the hydrophobic contact between $\mathrm{Phe}_{19}$ and $\mathrm{Leu}_{34}$ by introduction of backbone modifications, namely methylene or ethylene spacer or $N$-methylation of the amide, in both residues in different combinations (see Fig. 2). Two isotopic labeling schemes (light and dark gray spheres) were applied for the investigations of local structure and dynamics of $\mathrm{A} \beta_{40}$ fibrils by solid-state NMR.

knowledge can be useful for the development of small molecular weight drugs that feature exactly that property for preventing formation of toxic $A \beta$ structures. In our previous work, a rational library of relatively minor modifications was introduced to modify one of the most crucial molecular contacts in $A \beta_{40}$ fibrils between the two opposing $\beta$-strands, which provided important insights. In a series of studies, we systematically modified the $\mathrm{Phe}_{19}-\mathrm{Leu}_{34}$ hydrophobic contact (Fig. 1), which has been found in almost all structural studies of A $\beta_{40}$ fibrils ${ }^{13-16}$. Overall, these studies showed that the $\mathrm{A} \beta_{40}$ structure is very robust against almost any of the introduced modi-

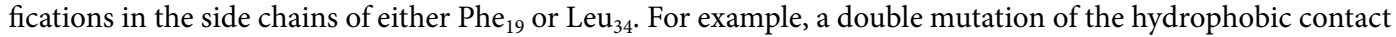
between $\mathrm{Phe}_{19}$ and $\mathrm{Leu}_{34}$ into two Lys residues (Phe ${ }_{19} \mathrm{Lys}$ and $\mathrm{Leu}_{34} \mathrm{Lys}$ ) introduced two positive charges, electrostatically repelling each other, which forced these side chains to move out of the hydrophobic core of the $\beta$-cross structure $^{24}$. However, the general morphology of the fibrils was only marginally influenced. An introduction of a proline into position $\mathrm{Phe}_{19}$ prolonged the fibrillation times (based on ThT fluorescence assay) dramatically ${ }^{25}$, but left the final fibril morphology largely unchanged. The only remarkable exception to the high tolerance of $\mathrm{A} \beta_{40}$ against any modification of the $\mathrm{Phe}_{19} / \mathrm{Leu}_{34}$ contact was that fibrillation was completely abrogated when a salt-bridge $\left(\mathrm{Lys}_{19}-\mathrm{Glu}_{34}\right)$ was introduced to replace the hydrophobic contact between $\mathrm{Phe}_{19}$ and $\mathrm{Leu}_{34}{ }^{25,26}$. Taken together, while local alterations in structure and dynamics of $A \beta_{40}$ have been observed, these studies showed that the $A \beta_{40}$ cross- $\beta$ structure is very robust, extremely stable and can tolerate and accommodate many local alterations in the physical interaction fields. However, any specific mutation influenced the toxicity of the $A \beta_{40}$ fibrils suggesting that the $\mathrm{Phe}_{19}$ and $\mathrm{Leu}_{34}$ is of crucial importance as an early folding contact in $\mathrm{A} \beta_{40}$ structure formation $^{27}$.

In the current study, we turn our attention to the backbone of $A \beta_{40}$ peptides and investigate the impact of two modifications of the $\mathrm{A} \beta_{40}$ peptide backbone at and around the important positions $\mathrm{Phe}_{19}$ and $\mathrm{Leu}_{34}$. These modifications correspond to $(i)$ an extended backbone structure (by the introduction of a methylene $(\mathbf{X}+\mathbf{1})$ or ethylene $(\mathbf{X}+\mathbf{2})$ spacer) and (ii) a peptide backbone $N$-methylation-Me-X) ( $-\mathrm{Me}-\mathrm{X})$ pattern (see Fig. 2). The rationale was that an extended backbone should induce a register shift to the standard in-register parallel $\beta$-sheet organization of the well-known steric zipper motif ${ }^{13,28}$ of $A \beta_{40}$ fibrils. Such a shift in register would challenge the inter- $\beta$-strand side chain contacts as well as backbone $\beta$-sheet hydrogen bridges. The $N$-methylation of the peptide backbone would disturb the intermolecular hydrogen bonds between neighboring $\beta$-sheets ${ }^{29-31}$. To achieve that, we used combinations of Phe, Leu, 3-amino-4-phenylbutanoic acid ( $\beta$-homo-Phe), 3-amino-5-methylhexanoic acid ( $\beta$-homo-Leu), 4-amino-5-phenylpentanoic acid ( $\gamma$-Phe), 4-amino-5-methylheptanoic acid ( $\gamma$-Leu), $N$-methyl-phenylalanine ( $N$-Me-Phe) and $N$-methyl-leucine $(N$-Me-Leu) as summarized in Figs. 1 and 2 . With these modifications, the amyloid peptides receive more degrees of freedom by either $(i)$ a more flexible backbone or (ii) a steric constraint, and the mutations are expected to introduce more structural variability into the system. This would $(i)$ influence the register between the two opposing $\beta$-strands in the $A \beta_{40}$ structure $e^{15,32-34}$ and (ii) interfere with the hydrogen bonding networks within the parallel intermolecular $\beta$-sheet arrangement ${ }^{29-31}$.

We used a broad repertoire of analytical techniques for the investigation of the amyloid fibrillation kinetics (thioflavin T (ThT) and crystal violet (CV) fluorescence spectroscopy), fibril morphology (transmission electron microscopy (TEM)), mesoscopic fibril packing parameters (X-ray diffraction), and fibril local structure and dynamics (solid-state nuclear magnetic resonance (NMR) spectroscopy). Further analyses include cellular toxicity studies (lactate dehydrogenase (LDH) release assay, 3-(4,5-dimethylthiazol-2-yl)-2,5-diphenyltetrazolium bromide (MTT) conversion assay, activated caspase- 3 and neurite length measurements) to determine the biological impact of the modifications and, thus, the relevance for pathologies observed in AD. 


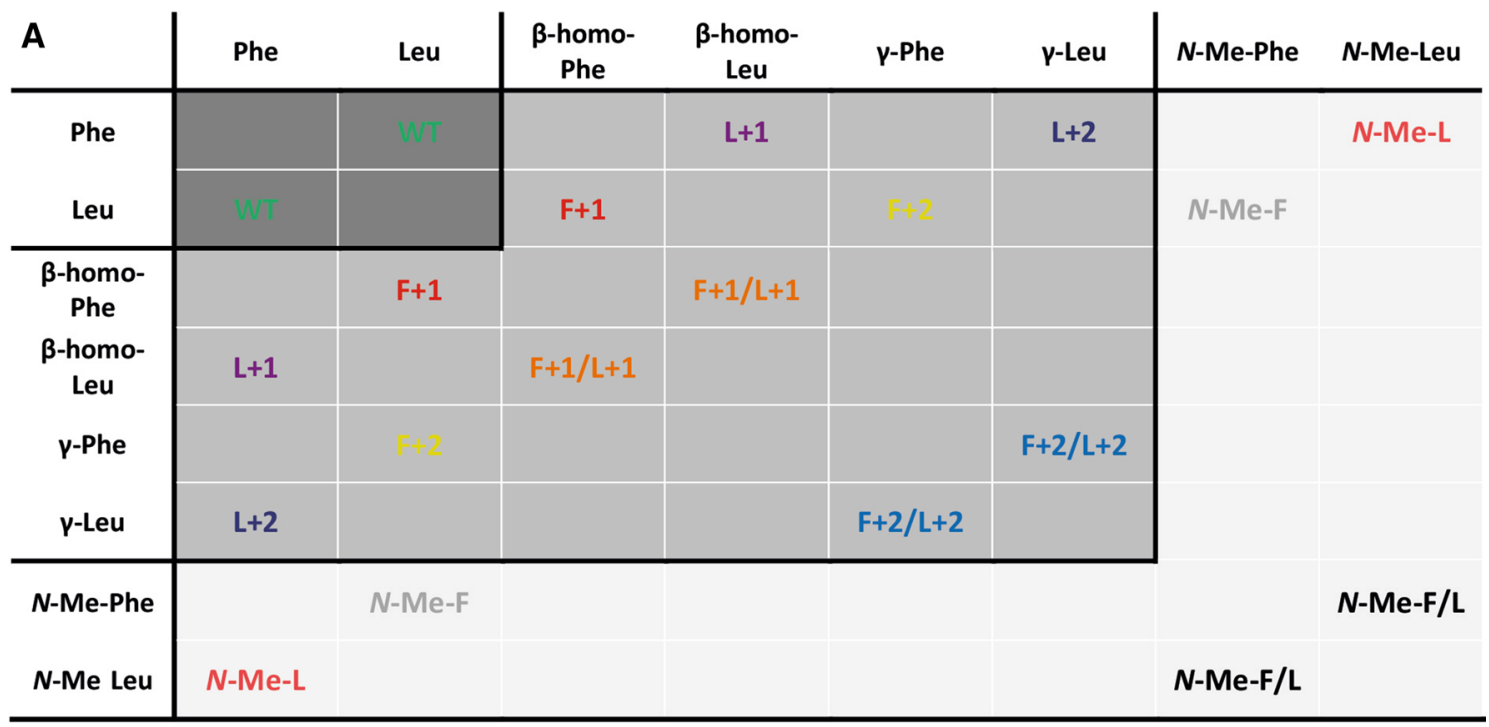

B

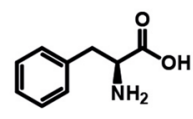

Phe (WT)

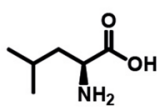

Leu (WT)

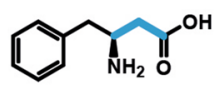

3-Amino-4-phenylbutanoic acid ( $\beta$-homo-Phe)<smiles>CC(C)C[C@H](N)CC(=O)O</smiles>
3-Amino-5-methylhexanoic acid
( $\beta$-homo-Leu)

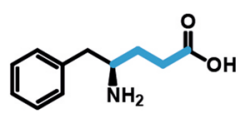

4-Amino-5-phenylpentanoic acid ( $\gamma$-Phe)

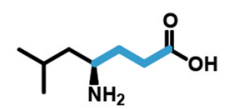

4-Amino-6-methylheptanoic acid ( $\gamma$-Leu)

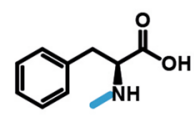

N-Me-Phe 19

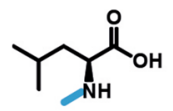

$\mathrm{N}-\mathrm{Me}-\mathrm{Leu}_{34}$

Figure 2. (A) Summary of the backbone mutation scheme applied to $A \beta_{40}$ peptides used in this study. The color code is used throughout the manuscript in the respective data. (B) Chemical structure of the backbone modified amino acids introduced into positions 19 and 34, respectively.

\section{Results}

Fibrillation kinetics using the ThT fluorescence assays. The fibrillation kinetics of the investigated mutant and wild type $A \beta_{40}$ peptides were followed by recording the thioflavin $T$ (ThT) fluorescence intensity over time which indicates formation of amyloid $\beta$ fibril structures ${ }^{35}$. The characteristic parameters that can be determined from a plot of the fluorescence intensity vs. time (see supplementary Fig. $S 1)$ are the lag time $\left(t_{\text {lag }}\right)$ and fibrillation time $\left(t_{\text {fib }}\right)$, which are presented in Fig. 3 for all peptide variants.

All $\mathrm{A} \beta_{40}$ variants with extended backbone modifications, except $\mathbf{F}+\mathbf{1} / \mathbf{L}+\mathbf{1}$, show the typical sigmoidal fluorescence intensity curves as a function of time (see Fig. S1, SI) consisting of the three characteristic phases: the lag phase, the fibrillation phase, and the plateau phase. Based on the results, $\mathbf{F}+2 / \mathrm{L}+2\left(t_{\mathrm{lag}}=3.3 \pm 1.0 \mathrm{~h}\right.$; $\left.t_{\mathrm{fib}}=9.1 \pm 1.9 \mathrm{~h}\right)$ shows a lag time shorter than the $\mathbf{W T}\left(t_{\mathrm{lag}}=6.7 \pm 1.1 \mathrm{~h} ; t_{\mathrm{fib}}=3.5 \pm 1.7 \mathrm{~h}\right)$, but a significantly longer fibrillation time until approaching the plateau phase, indicating that the increased degrees of freedom in the peptide backbone alter the energy landscape of the fibrillation process. The lag times for $\mathbf{F}+1\left(t_{\operatorname{lag}}=2.3 \pm 0.7 \mathrm{~h}\right.$; $\left.t_{\text {fib }}=2.3 \pm 1.1 \mathrm{~h}\right), \mathbf{F}+2\left(t_{\mathrm{lag}}=4.1 \pm 0.5 \mathrm{~h} ; t_{\mathrm{fib}}=4.5 \pm 1.1 \mathrm{~h}\right)$ and $\mathbf{L}+\mathbf{1}\left(t_{\mathrm{lag}}=4.0 \pm 0.4 \mathrm{~h} ; t_{\mathrm{fib}}=1.5 \pm 0.8 \mathrm{~h}\right)$ are shorter than for the WT, and $\mathbf{L}+2\left(t_{\mathrm{lag}}=6.7 \pm 0.6 \mathrm{~h} ; t_{\mathrm{fib}}=2.4 \pm 0.5 \mathrm{~h}\right)$ is in the same order of magnitude, showing that most of the mutations provide a stimulus for an earlier start of the fibrillation process. On the other hand, the fibrillation times are very similar.

Interestingly, the double mutations seem to have a rather strong impact on the fibrillation kinetics, as the $\mathrm{F}+\mathbf{1} / \mathrm{L}+\mathbf{1}$ variant shows two fibrillation phases, the first one starting immediately after dissolution in the fibrillation buffer reaching the plateau phase relatively fast and a second slower one starting after about $20 \mathrm{~h}$ (see supplementary Fig. S1). This behavior is reminiscent of the studies by Muschol and co-workers who concluded that sigmoidal kinetics indicate basically "oligomer-free" fibril formation, whereas in a biphasic growth the initial phase is dominated by globular oligomers ${ }^{36,37}$. For that purpose, they screened for an oligomer-specific dye and identified crystal violet $(\mathrm{CV})$ as such. Therefore, we conducted fibril formation assays with CV for WT, F+1/ $\mathbf{L}+\mathbf{1}$ and $\mathbf{F}+\mathbf{2} / \mathbf{L}+\mathbf{2}$ and found that for $\mathbf{F}+\mathbf{1} / \mathbf{L}+\mathbf{1}$ the $\mathrm{CV}$ fluorescence responses are indicative of fast oligomer formation with a constant concentration level up to $20 \mathrm{~h}$ which is not the case for the other two investigated peptides (Fig. S2, SI).

Noticeably, the backbone methyl modified $N$-Me-F and $N$-Me-F/L variants do not fibrillate at all under the applied conditions and $\mathrm{N}$-Me-L has a very extensive lag time of $135.7 \pm 18.5 \mathrm{~h}$ and a somewhat longer fibrillation time of $19.4 \pm 4.0 \mathrm{~h}$. This reveals that methylation of the amide group in the peptide backbone has a tremendous effect on the formation of fibrils, where disturbances at $\mathrm{Phe}_{19}$ seem to be more severe. This effect was also 

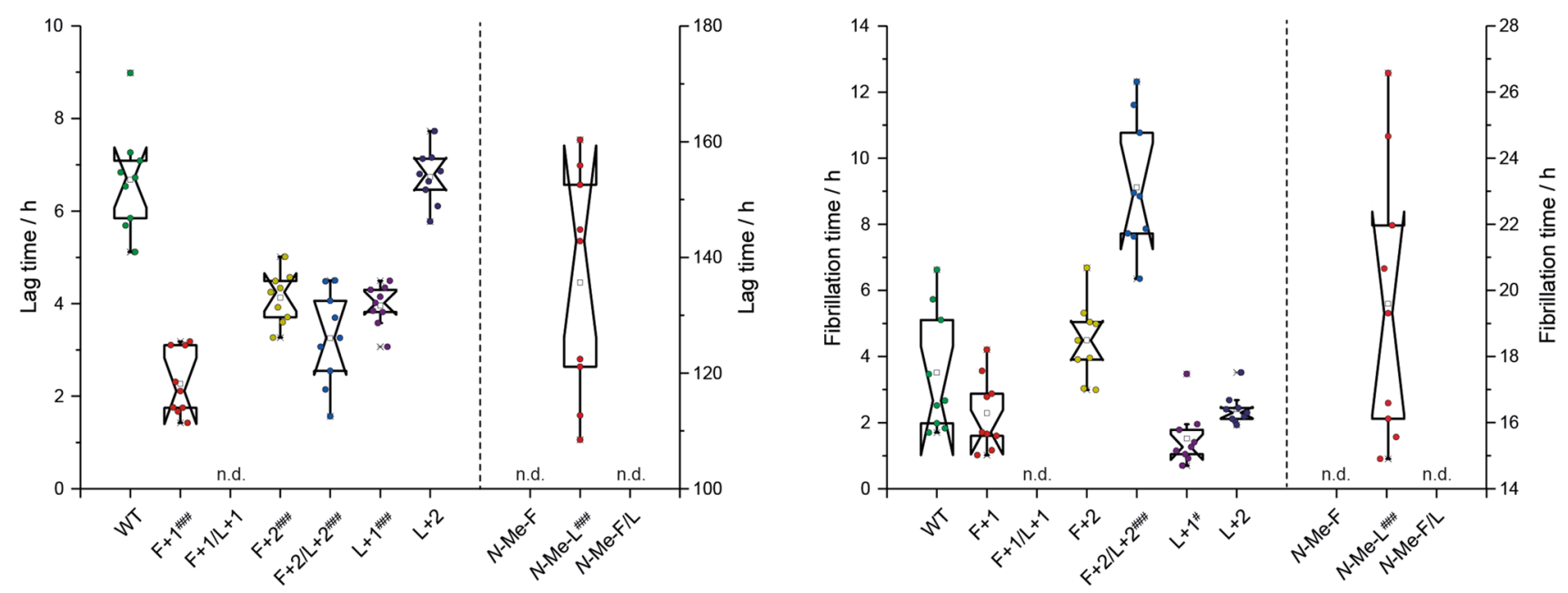

Figure 3. Box plot representation of the two characteristic parameters lag time (left) and fibrillation time (right) determined from ThT fluorescence fibrillation kinetics experiments. The peptide variants $\mathrm{N}-\mathrm{Me}-\mathrm{F}$ and $\mathbf{N}-\mathbf{M e}-\mathbf{F} / \mathbf{L}$ do not fibrillate, while data for $\mathbf{F}+\mathbf{1} / \mathbf{L}+\mathbf{1}$ could not be fitted with the applied function (n.d. means not determined). Data from three independent experiments with three replicates each are shown. Peptide concentration was $0.125 \mathrm{mg} \mathrm{mL}^{-1}$ in an aqueous $25 \mathrm{mM}$ sodium phosphate buffered solution (pH 7.4) containing $150 \mathrm{mM} \mathrm{NaCl}$ and $0.01 \%(\mathrm{w} / \mathrm{v}) \mathrm{NaN}_{3}$. All normalized fluorescence intensity vs. time plots are given in the supporting information (supplementary Fig. S1). Significance was tested applying a heteroscedastic Student's t-Test using two-tailed distributions, ${ }^{\#} \mathrm{p} \leq 0.05 ;{ }^{\# \#} \mathrm{p} \leq 0.01 ;{ }^{\# \#} \mathrm{p} \leq 0.001$ vs WT.

observed earlier by Meredith and co-workers ${ }^{30,31}$ and was related to inhibition of amyloid $\beta$ toxicity of some short peptides $^{38,39}$, from which a whole strategy of aggregation inhibitors in medicinal chemistry was developed ${ }^{40,41}$.

$A \beta_{40}$ fibril morphology investigated by transmission electron microscopy. To study the morphology of the $A \beta_{40}$ fibrils, transmission electron microscopy (TEM) experiments were performed on fibrils formed during the ThT fluorescence fibrillation assay (see supplementary Fig. S3 for TEM images). All mutants with extended backbones form fibrils, while only the $\mathrm{N}$-Me-L mutant among the $\mathrm{N}$-methylated ones fibrillated (Fig. 3). The fibril diameter, determined from the TEM images, of $\mathbf{F}+\mathbf{1}(14.3 \pm 1.1 \mathrm{~nm}), \mathbf{F}+\mathbf{2}(13.9 \pm 1.0 \mathrm{~nm})$, $\mathbf{F}+2 / \mathbf{L}+2(14.3 \pm 1.1 \mathrm{~nm})$ are in the same order of magnitude and slightly smaller than $N-\mathbf{M e}-\mathbf{L}(15.3 \pm 1.1 \mathrm{~nm})$ and the WT $(15.6 \pm 1.6 \mathrm{~nm})$, while $\mathbf{F}+\mathbf{1} / \mathbf{L}+\mathbf{1}(20.1 \pm 1.5 \mathrm{~nm}), \mathbf{L}+\mathbf{1}(20.9 \pm 1.6 \mathrm{~nm})$ and $\mathbf{L}+\mathbf{2}(21.4 \pm 1.6 \mathrm{~nm})$ form fibrils with a larger diameter (about $+5 \mathrm{~nm}$ ) (Fig. 4). Only the double mutants $\mathbf{F}+\mathbf{1} / \mathbf{L}+\mathbf{1}$ and $\mathbf{F}+\mathbf{2} / \mathbf{L}+\mathbf{2}$ also show additionally a minor population with larger diameter (about $+5 \mathrm{~nm}$, respectively; data not shown).

Furthermore, topological differences among the mutants were analyzed showing that the $\mathbf{W T}, \mathbf{F}+\mathbf{1}, \mathbf{F}+\mathbf{2}$, $\mathbf{F}+\mathbf{2} / \mathrm{L}+\mathbf{2}$ and the larger population of $\mathbf{F}+\mathbf{1} / \mathrm{L}+\mathbf{1}$ form fine and distinct fibrils, where the other mutants form fibrils reminding of crystalline needles grown together along the long side. Notably, some mutants are shorter in length $(\mathbf{F}+\mathbf{1}$, minor population of $\mathbf{F}+\mathbf{1} / \mathbf{L}+\mathbf{1}, \mathbf{F}+\mathbf{2}, \mathbf{L}+\mathbf{1}$ and $\mathbf{N}-\mathbf{M e}-\mathbf{L})$, than others (major population of $\mathbf{F}+\mathbf{1}$ / $\mathrm{L}+1, \mathrm{~F}+2 / \mathrm{L}+2$ and $\mathrm{L}+2)$.

Mesoscopic cross- $\beta$ structure investigated by X-ray diffraction. For X-ray powder diffraction measurements, samples of the respective $A \beta_{40}$ fibrils were mounted to nylon loops using oil and measured using $\mathrm{Cu} \mathrm{K} \alpha$ X-ray radiation $\left(\mathrm{Cu} \mathrm{K}_{\alpha}, \lambda=1.5406 \AA \AA\right.$ ). By applying Braggs law, the detected Debye cones, represented in the diffraction intensity vs $2 \theta$ plot (Fig. 5), could be transformed into the inter-sheet and inter-strand distances ${ }^{42}$. Relatively sharp reflections in the range of $2 \theta=14-18^{\circ}$ and at $21^{\circ}$ result from salts present in the amyloid samples.

All the mutants show an intense and relatively well-defined reflection assigned to inter-strand spacing $(4.7 \AA)$ which is characteristic for the cross- $\beta$ structure of amyloid fibrils (along growing direction) ${ }^{42,43}$. For WT, F+1 and $\mathbf{F}+\mathbf{2}$ this peak is relatively sharp, while for all the mutants, having a mutation at the $\mathrm{Leu}_{34}$ site, the peak is particularly broadened indicating more structural heterogeneity. Additionally, the signals for the inter-sheet distances are even more diffuse and less intense compared to $\mathbf{W T}, \mathbf{F}+\mathbf{1}$ and $\mathbf{F}+\mathbf{2}$. Both observations are a hint towards higher structural heterogeneity in the packing when the $\operatorname{Leu}_{34}$ is mutated. Within the series WT $(9.8 \AA)$, F+1 $(9.7 \AA)$, and $\mathbf{F}+\mathbf{2}(9.3 \AA)$ the packing becomes slightly tighter while the overall diffraction pattern remains similar. Interestingly, $\mathbf{L}+\mathbf{1}$ shows two separated reflections (11.2 and $8.3 \AA$ ), which is unique for this mutant with this particular clarity. In summary, especially Leu $_{34}$ site mutations introduce a type of perturbation into the fibril structure, which leads to shorter inter-sheet distances on an average, but with rather diffuse distributions.

Investigation of the local molecular structure of the mutated $A \beta_{40}$ fibrils by solid-state NMR spectroscopy. To obtain insights into the secondary structure on the level of individual amino acids, solidstate NMR spectra of the peptide variants that formed fibrils were recorded using two different isotopic $\left({ }^{13} \mathrm{C} /{ }^{15} \mathrm{~N}\right)$ labeling schemes (see Fig. 1). One of them was chosen for investigating the local influence of the mutations in the vicinity of the $\mathrm{Phe}_{19}$ mutation site (labeling scheme 1: $\mathrm{Val}_{18}, \mathrm{Phe}_{20}, \mathrm{Ala}_{21}, \mathrm{Gly}_{33}$ ). In the other case, the labeling 


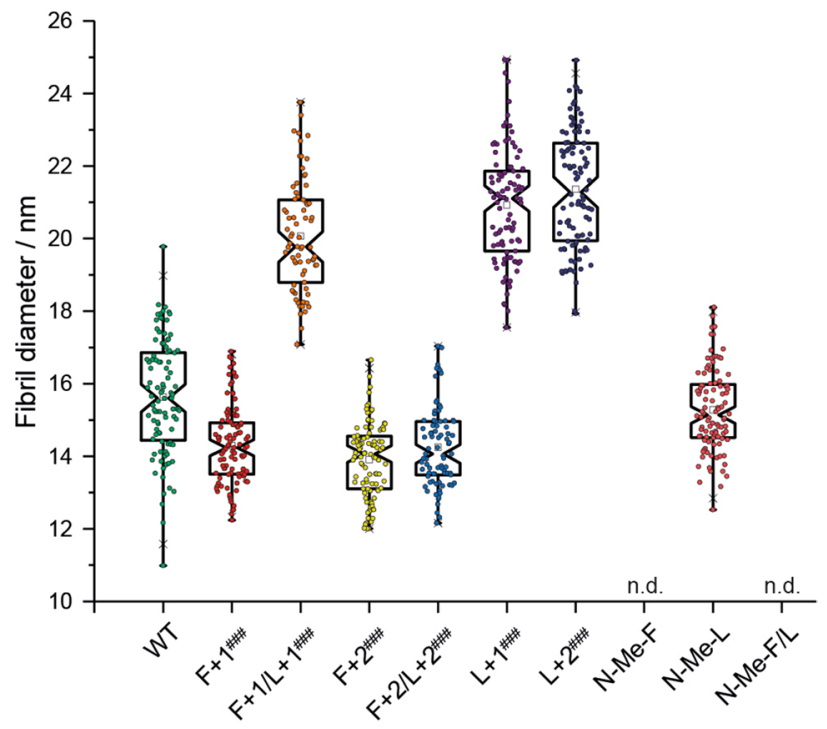

Figure 4. Box plot showing the diameters of fibrils formed from all $A \beta_{40}$ peptide variants determined based on TEM images. $N$-Me-F and $N$-Me-F/L do not fibrillate (n.d. means not determined); minor second fibril population of $\mathbf{F}+\mathbf{1} / \mathrm{L}+\mathbf{1}$ and $\mathrm{F}+\mathbf{2} / \mathrm{L}+\mathbf{2}$ not shown. Significance was tested applying a heteroscedastic Student's t-Test using two-tailed distributions, ${ }^{\#} \mathrm{p} \leq 0.05 ;{ }^{\# \#} \mathrm{p} \leq 0.01 ;{ }^{\# \# \#} \mathrm{p} \leq 0.001$ vs WT.
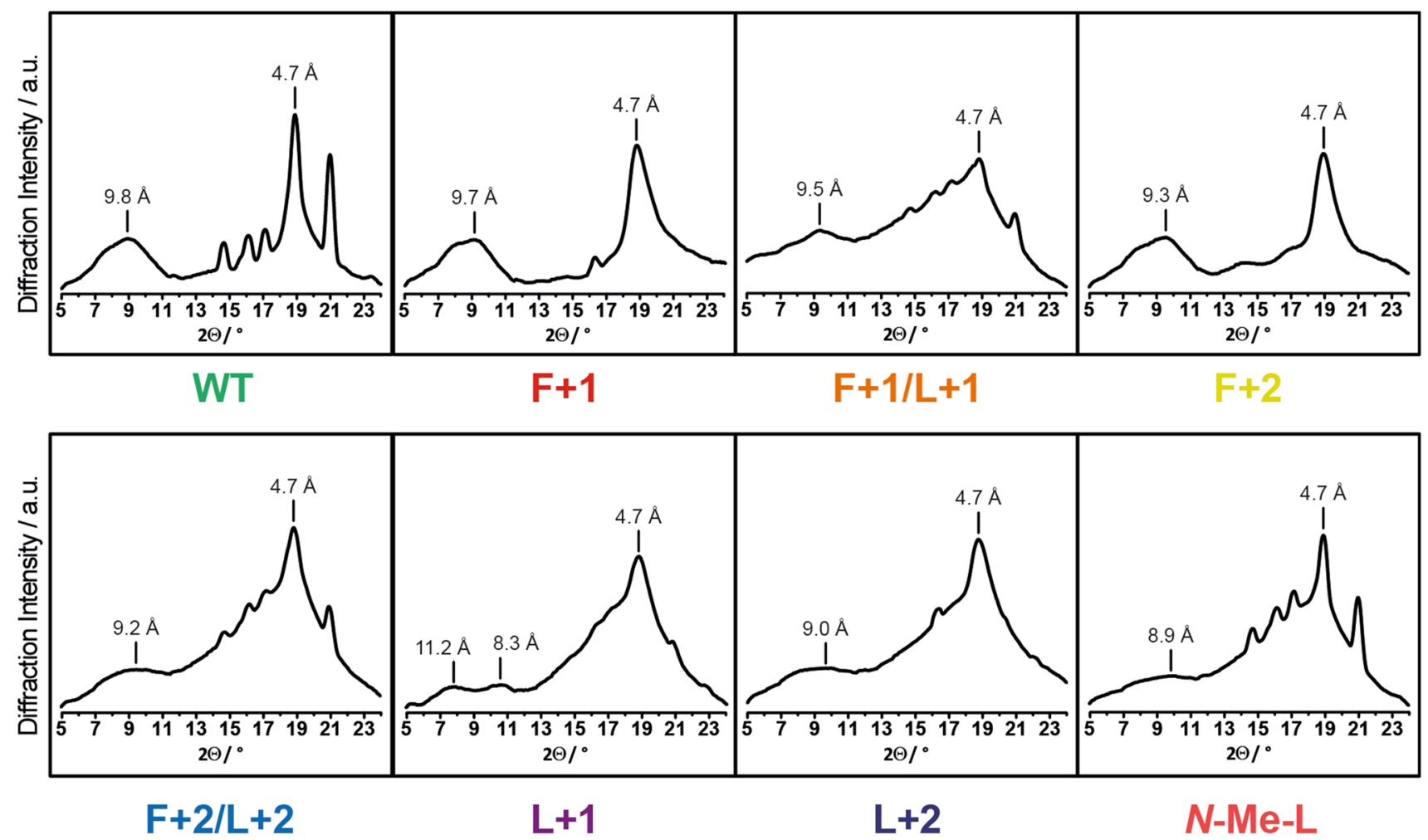

Figure 5. X-ray diffraction patterns of fibrils formed from the $\mathrm{A} \beta_{40}$ variants. Characteristic inter-sheet (8.3-11.2 $\AA)$ and inter-strand $(4.7 \AA)$ distances are assigned. Other reflections in the range of $2 \theta=14-18^{\circ}$ and at $21^{\circ}$ result from salts present in the amyloid samples and are not of significance.

scheme involving $\mathrm{Phe}_{19}, \mathrm{Ala}_{21}, \mathrm{Ile}_{32}, \mathrm{Val}_{36}$ (labeling scheme 2) concentrates on the mutations on the Leu site. $_{34}$ It was designed to identify potential inter- $\beta$-strand contacts caused by peptide backbone register shifts $(\mathbf{L}+\mathbf{1})$ or peptide backbone $\mathrm{N}$-methylation $(\mathrm{N}-\mathrm{Me}-\mathrm{L})$. The assignments of the signals of the aforementioned uniformly ${ }^{13} \mathrm{C} /{ }^{15} \mathrm{~N}$ labeled amino acids were done by means of either co-acquisition of ${ }^{13} \mathrm{C}-{ }^{13} \mathrm{C}$ DARR and ${ }^{13} \mathrm{Ca}-{ }^{15} \mathrm{~N}$ correlation NMR experiments ${ }^{22}$ or ${ }^{13} \mathrm{C}-{ }^{13} \mathrm{C}$ DARR experiments. A summary of all ${ }^{13} \mathrm{C}$ and ${ }^{15} \mathrm{~N}$ chemical shifts of the 


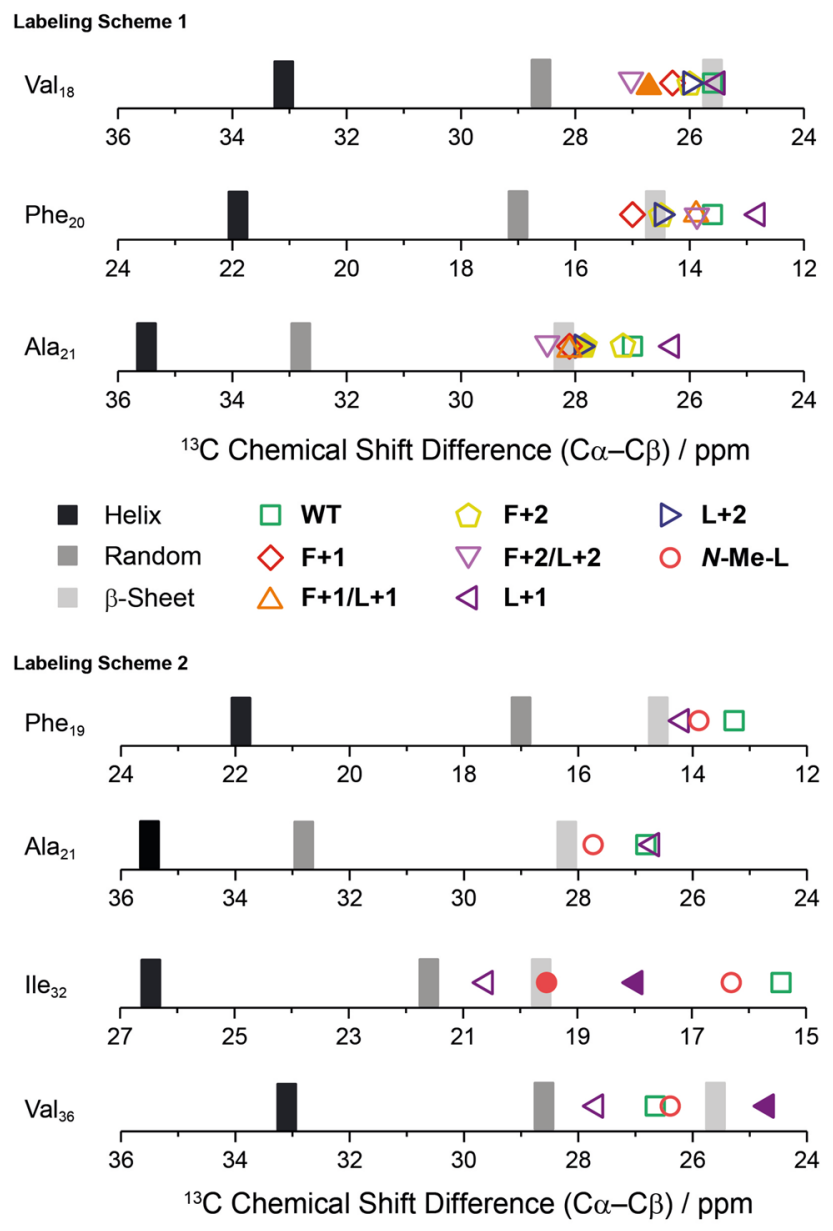

Figure 6. Overview of the ${ }^{13} \mathrm{C} \alpha-{ }^{13} \mathrm{C} \beta$ chemical shift differences of the labeled amino acids subdivided into the two applied labeling schemes: $\mathrm{Val}_{18}, \mathrm{Phe}_{20}, \mathrm{Ala}_{21}, \mathrm{Gly}_{33}$ (labeling scheme 1) and $\mathrm{Phe}_{19}, \mathrm{Ala}_{21}, \mathrm{Ile}_{32}, \mathrm{Val}_{36}$ (labeling scheme 2) derived from ${ }^{13} \mathrm{C}-{ }^{13} \mathrm{C}$ DARR NMR experiments. Gly ${ }_{33}$ is not shown because it is lacking a $\mathrm{C} \beta$ atom. The bars represent the reference values of $\alpha$-helix (black), random coil (gray) and $\beta$-sheet (light gray) secondary structure as reported in the literature ${ }^{44}$. Experimental data is given as varying symbols in the usual color code according to the legend. The standard error for determination of chemical shifts from ${ }^{13} \mathrm{C}-{ }^{13} \mathrm{C}$ DARR NMR experiments is $\pm 0.5 \mathrm{ppm}$. Other conformations, if applicable, are shown as filled forms in the respective color and shape (polymorphs of $\mathrm{Val}_{18}$ in $\mathbf{F}+\mathbf{1} / \mathbf{L}+\mathbf{1}$ (labeling scheme 1) are identical).

labeled nuclei are listed in supplementary Tables S1 and S2. Calibration-independent differences of the ${ }^{13} \mathrm{Ca}$ and ${ }^{13} \mathrm{C} \beta$ signals are reported for both labeling schemes, which are characteristic for the local secondary structure of the respective amino acids (Fig. 6) ${ }^{44}$. Some of the mutants with labeling scheme 1, namely $\mathbf{L}+\mathbf{1}\left(\mathrm{Gly}_{33}\right), \mathbf{F}+\mathbf{2}$ $\left(\mathrm{Ala}_{21}\right), \mathbf{F}+\mathbf{1} / \mathbf{L}+\mathbf{1}\left(\mathrm{Ala}_{21}, \mathrm{Gly}_{33}\right)$ and $\mathbf{F}+\mathbf{2} / \mathbf{L}+\mathbf{2}\left(\mathrm{Gly}_{33}\right)$, as well as with labeling scheme 2, $\mathbf{L}+\mathbf{1}\left(\mathrm{Ile}_{32}, \mathrm{Val}_{36}\right)$ and $\mathbf{N}$-Me-L $\left(\mathrm{Ile}_{32}\right.$ ), show polymorphisms while WT, $\mathbf{L}+\mathbf{2}$ and $\mathbf{F}+\mathbf{1}$ do not (supplementary Tables S1 and S2). This highlights again the higher degree of freedom in some modified $\mathrm{A} \beta$ peptides allowing diverse modification and possibly multiple interactions ${ }^{45,46}$. However, no conclusive pattern among the investigated mutants could be found in this regard.

In almost all the mutants, except for $\mathbf{L}+\mathbf{1}$, the signal for the carbonyl group (CO) could not be detected in the ${ }^{13} \mathrm{C}$ NMR spectra for $\mathrm{Gly}_{33}$ (supplementary Table S1), so that it cannot be used as a parameter for the local impact of the mutation on Gly ${ }_{33}$. The ${ }^{15} \mathrm{~N}$ NMR signals for $\mathrm{Ala}_{21}$ in the double mutants, $\mathbf{F}+\mathbf{1} / \mathbf{L}+\mathbf{1}$ and $\mathbf{F}+\mathbf{2} / \mathbf{L}+\mathbf{2}$, are relatively strongly upfield shifted (119.4 and $118.7 \mathrm{ppm}$, respectively), which indicates effects on hydrogenbonding between $\beta$-strands (supplementary Table S1). In labeling scheme 1, all investigated mutants show $\beta$-sheet secondary structures, suggesting that the induced perturbation by extended backbones does not influence the local secondary structure around the $\mathrm{Phe}_{19}$ mutation site compared to the WT. However, $\mathbf{L}+\mathbf{1}$ seems to be special in the sense that its ${ }^{13} \mathrm{Ca}-{ }^{13} \mathrm{C} \beta$ chemical shift differences, at least for $\mathrm{Phe}_{20}$ and $\mathrm{Ala}_{21}$, is significantly smaller than for WT. Therefore, $\mathbf{L}+\mathbf{1}$ was chosen to be investigated in labeling scheme 2 together with $\mathbf{N}$-Me-L. Their ${ }^{13} \mathrm{Ca}-{ }^{13} \mathrm{C} \beta$ chemical shift difference values for amino acids $\mathrm{Phe}_{19}(\mathbf{L}+\mathbf{1}: 13.9 \mathrm{ppm}$; $\mathbf{N}$-Me-L: $14.1 \mathrm{ppm})$ and $\mathrm{Ala}_{21}$ (L+1: 26.6 ppm; $N$-Me-L: $27.4 \mathrm{ppm}$ ) are similar as for WT (13.2 and $26.7 \mathrm{ppm}$, respectively) but differ relevantly for $\mathrm{Ile}_{32}$ and $\mathrm{Val}_{36}$ (Fig. 6). Interestingly, the two conformations of $\mathrm{Ile}_{32}(\mathrm{~L}+\mathbf{1}: 18.0$ and $20.7 \mathrm{ppm} ; \mathrm{N}$-Me-L: 16.3 and $19.6 \mathrm{ppm})$ or $\mathrm{Val}_{36}(\mathbf{L}+\mathbf{1}: 24.8$ and $27.7 \mathrm{ppm})$ differ from each other and from the WT. For $\mathbf{L}+\mathbf{1}$ both conformers 
WT (600 ms DARR mixing time)

$N$-Me-L (600 ms DARR mixing time)

L+1 (600 ms DARR mixing time)<smiles>CCC(C)[C@H](N)C(=O)O</smiles>
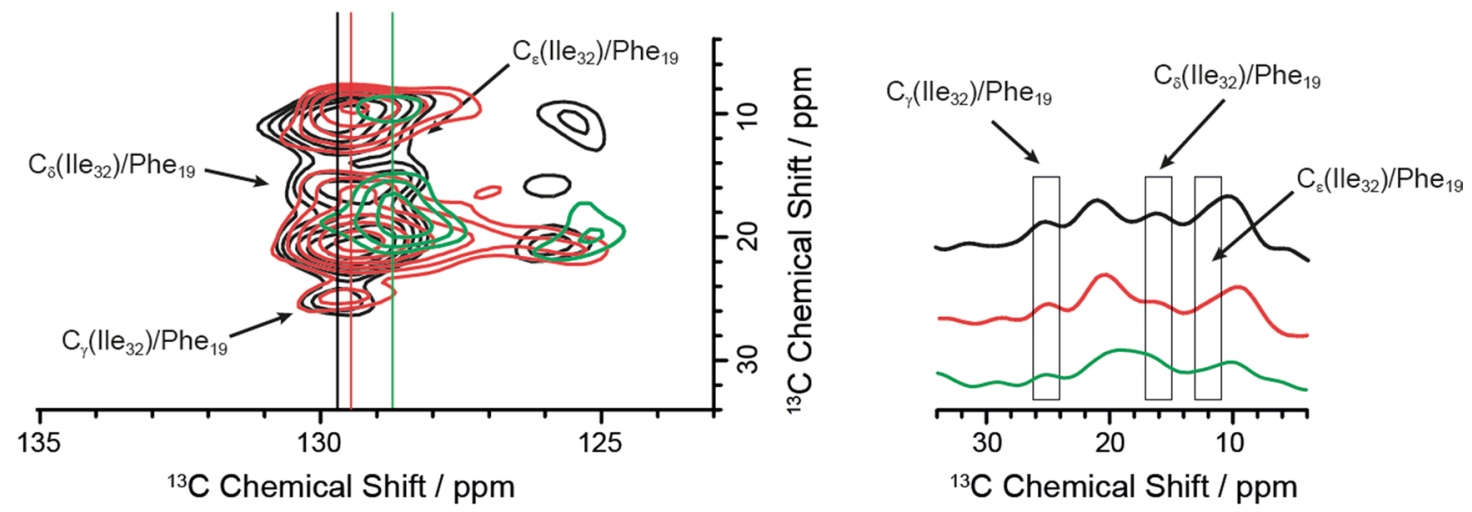

Figure 7. Sections from the contour plot of ${ }^{13} \mathrm{C}-{ }^{13} \mathrm{C}$ DARR NMR spectra $\left(30^{\circ} \mathrm{C}\right.$, MAS frequency of $\left.11,777 \mathrm{~Hz}\right)$ of $\mathbf{L}+\mathbf{1}$ (129.6 ppm), $\mathbf{N}$-Me-L (129.4 ppm) and WT (128.7 ppm) using labeling scheme 2 showing a structural change upon mutation at $\mathrm{Leu}_{34}$. Left: schematic molecular structure of $\mathrm{Ala}_{21}$ and $\mathrm{Ile}_{32}$ including labeling; center: contour plot of ${ }^{13} \mathrm{C}-{ }^{13} \mathrm{C}$ DARR NMR spectra for $+\mathbf{1}$ (black), $\mathbf{N}$-Me-L (red) and WT (green); right: projection of ${ }^{13} \mathrm{C}-{ }^{13} \mathrm{C}$ DARR NMR spectra for L+1 (black), $\mathbf{N}$-Me-L (red) and WT (green) along y-axis.

even vary between predominantly random coil and $\beta$-sheet structure. Polymorphism or structural variation on the molecular level occurs frequently in amyloid fibril formation and may even correlate with diverging progress of the diseases among patients ${ }^{47-49}$. In conclusion, the local secondary structure around the Leu mutation site $_{34}$ is more sensitive towards backbone mutations of these types than $\mathrm{Phe}_{19}$.

In addition to amyloid structure determination, NMR spectroscopy is a very sensitive tool to obtain information on molecular dynamics. The order parameter $(S)$ derived from the measurement of motional averaged ${ }^{1} \mathrm{H}-{ }^{13} \mathrm{C}$ dipolar couplings using DipShift experiments ${ }^{50,51}$ yields information on the motional amplitude of a given $\mathrm{C}-\mathrm{H}$ bond vector. The molecular order parameters of the labeled residues in the $\mathrm{A} \beta_{40}$ variants are shown in supplementary Fig. S4. Overall, no drastic changes in the order parameters throughout the variants using labeling scheme 1 were observed. For amino acid $\mathrm{Gly}_{33}$ the $\mathrm{Ca}-\mathrm{Ha}$ bond vector became a bit more rigid compared to the WT, when any type of mutation was introduced, but interestingly the conformers for $\mathrm{Gly}_{33}$ for $\mathbf{F}+\mathbf{1} / \mathrm{L}+\mathbf{1}$ or $\mathbf{L}+\mathbf{1}$ differ in mobility. Worth noticing, in $\mathbf{F}+\mathbf{1} / \mathbf{L}+\mathbf{1}$ the phenyl ring of $\mathrm{Phe}_{20}$ is slightly more rigid compared to WT and the other mutants. For labeling scheme 2, the observations are relatively similar, no drastic changes were observed. The only detail worth highlighting is that for $\mathbf{L}+\mathbf{1}$ all carbons show a tendency for higher rigidity, except for the phenyl ring in $\mathrm{Phe}_{19}$, where the amplitude for the ring motions increased a bit, which might give a hint towards the influence of a mutation at $\mathrm{Leu}_{34}$ onto its crucial contact partner, the $\mathrm{Phe}_{19}$.

In order to examine a potential register-shift between the $\mathrm{Phe}_{19}$ and $\mathrm{Leu}_{34}$ contact in the opposing $\beta$-strands (Fig. 1) induced by either backbone extension or backbone $N$-methylation, we exemplarily chose $\mathbf{L}+\mathbf{1}$ and $\mathbf{N}$-Me$\mathbf{L}$ for further NMR analysis. To this end, the amino acids $\mathrm{Phe}_{19}, \mathrm{Ala}_{21}, \mathrm{Ile}_{32}, \mathrm{Val}_{36}$ (labeling scheme 2) were ${ }^{13} \mathrm{C}$ and ${ }^{15} \mathrm{~N}$ isotopically labeled, which only allows for mutations at $\mathrm{Leu}_{34} \cdot{ }^{13} \mathrm{C}-{ }^{13} \mathrm{C}$ DARR NMR experiments were performed with mixing times of $600 \mathrm{~ms}$ to probe the long distance and $50 \mathrm{~ms}$ for short distance contacts. For $\mathbf{L}+\mathbf{1}$ the cross peaks at around 129.6/12-25 ppm, which are assigned to side chain contacts between the labeled side chains of $\mathrm{Ile}_{32}$ and $\mathrm{Phe}_{19}$, are only detected in the DARR NMR spectrum recorded with long $600 \mathrm{~ms}$ mixing time (Fig. 7, center). The WT, on the other hand, also shows this contact (Fig. 7, right), although the chemical shift of the Phe ring system is slightly lower. However, comparing the recorded NMR spectra for $\mathbf{L}+\mathbf{1}$ and $\mathrm{N}$-Me-L, the same contact between $\mathrm{Ile}_{32}$ and $\mathrm{Phe}_{19}$ was detected also for $\mathbf{N}$-Me-L (Fig. 7, center). This leads to the conclusion that no significant alterations in the sidechain zipper motif or a register shift are induced by the backbone modifications. But we note that the ring of $\mathrm{Phe}_{19}$ is also in contact with the side chain of Ile ${ }_{32}$ which was not reported before.

Cellular toxicity assays of mutated $A \boldsymbol{\beta}$ fibrils. To probe the biological activity of the individual $\mathrm{A} \beta_{40}$ variants, four different cell culture-based experiments were conducted (Fig. 8). In a first assay, the MTT (3-(4,5-dimethylthiazol-2-yl)-2,5-diphenyltetrazolium bromide) conversion for mitochondrial activity was performed which provides information about the proportion of metabolically active cells (upper left). Noticeably, $\mathbf{F}+\mathbf{1} / \mathbf{L}+\mathbf{1}$ has the clearest negative impact on the cell viability compared to control and $\mathbf{W T}$ among all the mutants. Same is true for the second type of cell viability testing, being the lactate dehydrogenase (LDH) assay. It is based on the release of the cytosolic enzyme LDH into the cell culture medium upon damage to the plasma membrane (indicating cell death). For that, $\mathbf{F}+\mathbf{1} / \mathbf{L}+\mathbf{1}$ exhibit a considerably destructive effect on the cell membrane integrity, while only $\mathbf{L}+\mathbf{2}$ is also significantly different to the control and WT, but not as pronounced compared to $\mathbf{F}+\mathbf{1} / \mathbf{L}+\mathbf{1}$.

The outcome of the immunocytochemical staining for activated caspase-3, which is a protein involved in apoptotic neuronal cell death program, is interesting due to the apparently protective activity of the $N$-methylated 

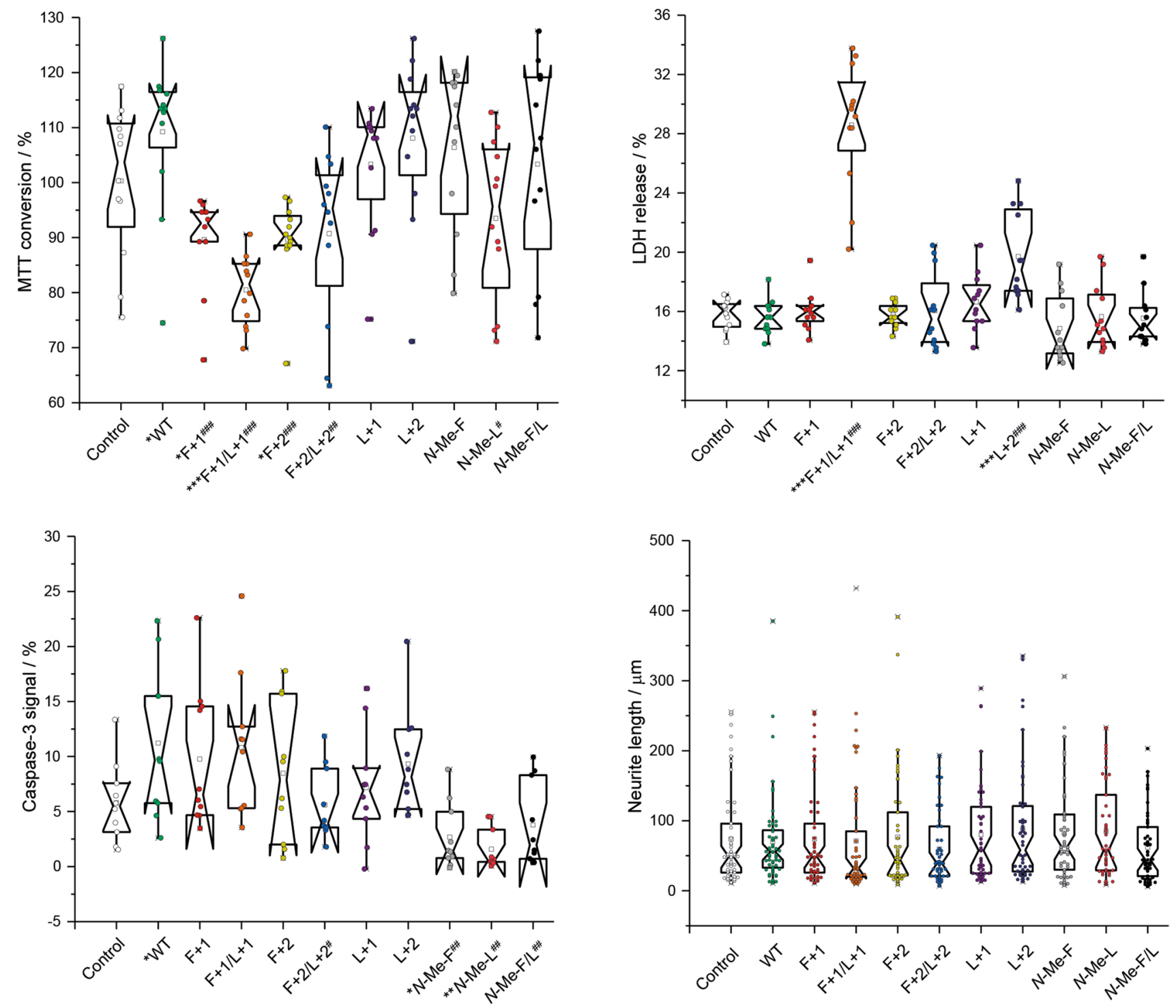

Figure 8. Box plots showing results from toxicity studies of all $A \beta_{40}$ peptide variants. The MTT conversion assay (upper left) represents the proportion of metabolically active cells (alive) upon exposure to $A \beta_{40}$ peptide variants; the $\mathrm{LDH}$ release (upper right) is indicative for plasma membrane disruption (dead cells) under the same conditions; caspase- 3 staining (bottom left) is used to investigate one of the possible pathways towards cell apoptosis; neurite length (bottom right) measurements are used to examine the effect of all $\mathrm{A} \beta_{40}$ peptide variants on the outgrowth of neurites and thus the wellbeing under the applied conditions. Mutant $\mathbf{F}+\mathbf{1} / \mathbf{L}+\mathbf{1}$ stands out in MTT and LDH, while in the caspase-3 staining the $N$-methylated variants show protective effects. The neurite outgrowth behavior is not significantly impacted by any of the mutants. Significance was tested applying a heteroscedastic Student's t-Test using two-tailed distributions, ${ }^{\star} \mathrm{p} \leq 0.05 ;{ }^{* \star} \mathrm{p} \leq 0.01 ;{ }^{* *} \mathrm{p} \leq 0.001$ vs control; ${ }^{*}$ vs WT.

peptides, namely $\mathbf{N}$-Me-F (supplementary Table S1), $\boldsymbol{N}$-Me-L (supplementary Table S1) and $\mathbf{N}$-Me-F/L (supplementary Table $\mathrm{S} 1$ ), by suppressing the caspase-3 activation compared to control.

Neurite length (in $\mu \mathrm{m}$ ) as a marker of neuronal viability was measured after incubation with the mutant peptides. However, no significant differences were detected (Fig. 8) indicating no impact of the individual A $\beta_{40}$ variants on this aspect of neuronal wellbeing of the surviving neurons.

\section{Discussion}

The formation of amyloid fibrils, which is the process of conversion of soluble peptide monomers into insoluble aggregates with fibrillar structure, follows the widely accepted nucleation-dependent polymerization model ${ }^{18,19,52,53}$. Recent research has shown that the individual aggregation pathways of proteins and peptides can be very complex and there are several detours in addition to the sigmoidal kinetic fibrillation behavior, indicating that local structural minima exist on the free energy map ${ }^{36,54}$. This is an intrinsic property of the funnel-shaped free energy landscape of amyloid formation ${ }^{55,56}$. Nevertheless, various folding pathways lead to a highly stable 
low energy structure that is dominated by the cross- $\beta$ motif. In our approach, we probe how the folding of $A \beta_{40}$ peptides is influenced by point mutations at $\mathrm{Phe}_{19}$ and $\mathrm{Leu}_{34}$, which form an important early hydrophobic contact in the $A \beta_{40}$ folding process. These rational modifications can provide information on key points on the energy landscape of the fibril formation process. Our former activities involved, among others, alterations of the Phe ${ }_{19}$ and/or Leu 34 side chains ${ }^{25,57-59}$. In the current study, we focus our attention to the peptide backbone, which we modified by $(i)$ extension in the backbone structure by introduction of methylene $(\mathbf{X}+\mathbf{1})$ or ethylene $(\mathbf{X}+\mathbf{2})$ spacers and (ii) $N$-methylation of the backbone amide groups $(\boldsymbol{N} \text {-Me-X (supplementary Table S1) })^{60}($ Fig. 2$)$. In these peptide variants, the backbone extension increases the degrees of freedom in the peptide backbone and could perturb the ordered in-register hydrophobic zipper structure motif. The $N$-methylation of the amide abolishes the formation of the intermolecular hydrogen bond between neighboring $\beta$-strands at the respective mutation sites.

Our previous work on fibril formation of side chain modified $A \beta_{40}$ peptides led us to conclude that the amyloid structure is extremely robust against a multitude of perturbations introduced by individual natural and non-natural side chain modifications ${ }^{25,57-59}$. This conclusion also holds for the $\mathrm{A} \beta_{40}$ peptides with backbone extensions as applied here. While moderate alterations in the fibrillation kinetics (Fig. 3), fibril morphology (Fig. 4) and some heterogeneity of the cross- $\beta$ structure (Fig. 5) are observed, the general $\beta$-sheet backbone secondary structure and the cross- $\beta$ conformation are essentially not influenced by these mutations. The only exception is the $\mathbf{L}+\mathbf{1}$ variant, where $\mathrm{Ile}_{32}$ shows some local random coil structure. Overall, the steric-zipper motif of the side chains $s^{33,60}$ that describes the interlocking of the amino acid residues along with the intermolecular hydrogen bond patterns remain the dominating structure forming principle also in fibrils of backbone extended $\mathrm{A} \beta_{40}$ peptides. Thereby, the side chains remain in a tightly packed conformation as confirmed by high order parameters determined in DipShift NMR experiments indicating low conformational flexibility. Although backbone extensions provide additional degrees of freedom, the interlocking of the side chains is the dominating motif that remains largely unchanged. There are some alterations worth mentioning in this context, though: first, there is an increasing amount of structural polymorphism observed in the ${ }^{13} \mathrm{C} N M R$ spectra of some of the $\mathrm{A} \beta_{40}$ mutants, which demonstrates increased structural heterogeneity of the fibrils of mutated $\mathrm{A} \beta_{40}$ peptides ${ }^{46,49}$. This is confirmed by noticeably highfield-shifted ${ }^{15} \mathrm{~N}$ NMR signals of $\mathrm{Ala}_{21}$ in the double-mutants $\mathbf{F}+\mathbf{1} / \mathbf{L}+\mathbf{1}$ and F+2/L+2 (119.4 ppm, 118.7 ppm, respectively, vs. $126.1 \mathrm{ppm}$ in WT; NMR labeling scheme 1). Also, variant $\mathbf{L}+\mathbf{1}$ showed some structural alterations towards random coil structure of $\mathrm{Ile}_{32}$. For this variant, also a somewhat altered side chain packing was observed. Inversely, the lag times for the backbone extension variants in the ThT fibrillation kinetics are overall shorter as compared to the WT, while the fibrillation times are in the same order of magnitude. The backbone extension modification might thus even lower the activation energy barrier for early nucleation. In the fluorescence fibrillation plots, the double mutants, $F+1 / L+1$ and $F+2 / L+2$, show fibrillation kinetics diverging from normal sigmoidal curves under the applied conditions. For $F+2 / L+2$, it is reminiscent of kinetics based on catalyzed nucleation (e.g. seeding $)^{61}$, where the "seed" is formed during the lag time made from $\mathbf{F}+2 / \mathrm{L}+2$ itself, which is apparently attributed to this specific combination of backbone modifications. ThT fibrillation curves of $\mathbf{F}+\mathbf{1} / \mathbf{L}+\mathbf{1}$ look like two step fibrillation kinetics resembling curves from the literature on oligomer and fibril formations ${ }^{37}$. Kinetic fluorescence assays with an oligomer-selective dye (crystal violet, CV) revealed the presence of oligomers in the first $20 \mathrm{~h}$ of fibrillation ${ }^{37}$ (Fig. S2, SI). A hint towards understanding this abnormal behavior has been noticed in the difference of the ${ }^{15} \mathrm{~N}$ chemical shift for $\mathrm{Ala}_{21}$ for both the mutants with respect to the other variants and the WT. The potential existence of oligomeric species could be associated with the very effective membrane disruption ability of this mutant (Fig. 8), as oligomeric amyloid species are discussed as being the villains in cell toxicity ${ }^{62-66}$. Indirectly, an attenuating effect of $\mathbf{F}+\mathbf{1} / \mathbf{L}+\mathbf{1}$ on the MTT conversion by mitochondria is probably also related to the membrane disruption ability rather than mechanisms activating mitochondrial apoptotic pathways such as caspase- 3 activation.

In contrast to the moderate influence of the backbone extensions on $A \beta_{40}$ fibril formation and structure, the $N$-methylation modification of the peptide backbone causes a more severe interference with $\mathrm{A} \beta_{40}$ structure formation. $N$-methylation is one of the strategies to stabilize peptides against proteolysis and makes them more water soluble ${ }^{31,40}$. Likewise, methylation that interferes with intermolecular hydrogen bond formation is used for the design of amyloid- $\beta$ aggregation inhibitors ${ }^{67,68}$. There are at least three identified ways how $N$-methylation impairs protein aggregation: $(i)$ replacement of the amide proton cuts the hydrogen-bonding possibility between two neighboring $\beta$-strands; (ii) prevention of regular packing through steric hindrance (higher steric demand) and (iii) tertiary amides favoring trans-conformation leading to $\beta$-strand conformation, which, in this case, does not disturb the secondary structure ${ }^{69}$. Thus, the current results fit into the picture that fibrillation kinetics are either completely blocked ( $N$-Me-F, $N$-Me-F/L) or greatly slowed down $(\boldsymbol{N}-\mathbf{M e}-\mathrm{L})$. In the literature, examples by Meredith and co-workers, who used two times two $N$-methylated amino acids (2NMe(NTerm): residues 17 and 19; $2 \mathrm{NMe}(\mathrm{CTerm})$ : residues 37 and 39), fibrils could still be formed, although significantly slower than in absence of the modification ${ }^{29}$. Only four $\mathrm{N}$-methylated amino acids in the same peptide could prevent the fibrils from their formation. Noticeably, they could show that the $\beta$-sheet secondary structure for the respective strands is disrupted independently from each other according to their modification pattern, while $N$-methylation at position 17 and 19 has a higher impact on the fibril formation process, as it is true also for $N$-Me-F and $N-\mathbf{M e}-\mathbf{F} / \mathbf{L}$ compared to $\mathrm{N}$-Me-L. However, the striking difference is that in our case $\mathrm{N}$-methylation at only one $\left(\mathrm{Phe}_{19}\right)$ or two residues $\left(\mathrm{Phe}_{19} / \mathrm{Leu}_{34}\right.$ ), which were identified to be a critical early folding contact in fibril extension ${ }^{27}$, are sufficient to prevent from fibril formation. The protective behavior of $N-\mathrm{Me}-\mathrm{F}, \mathrm{N}-\mathrm{Me}-\mathrm{L}$ and $\mathrm{N}-\mathrm{Me}-\mathrm{F} / \mathrm{L}$ counteracting cytotoxicity is expressed in the assay measuring caspase- 3 activity, where they significantly decrease caspase- 3 activation compared to the WT and partly to the control. This is in alignment with other $N$-methylated peptides in the literature ${ }^{70}$.

With the experimental techniques applied, no conclusive statement about the underlying $\mathrm{A} \beta_{40}$ structural model, be it the U-shape ( $\beta$ arcades) ${ }^{32}$, C-shape (e.g. ex vivo $A \beta_{40}$ fibril, PDB: $\left.6 S H S\right)^{71}$, or the recently found extended shape model $^{72}$, can be made. The $\mathrm{A} \beta_{40} \mathrm{Glu}_{22} \Delta$ (Iowa mutant ${ }^{73}$ structure (PDB: $2 \mathrm{MVX}$ ) and the threefold 
symmetric $A \beta_{40}$ structure (PDB: $2 \mathrm{M} 4 \mathrm{~J}$ ) by Lu et al. ${ }^{74}$, however, can be excluded, since $\mathrm{Ala}_{21}$ and Phe ${ }_{20}$ show $\mathrm{C} \alpha-\mathrm{C} \beta$ chemical shift differences characteristic for $\beta$-sheet structure. Nevertheless, for $\mathbf{L}+\mathbf{1}$ and $\mathbf{N}-\mathbf{M e}-\mathbf{L}$ contacts between $\mathrm{Phe}_{19}$ and $\mathrm{Ile}_{36}$ (see NMR labeling scheme 2 and Fig. 7) could be found, which points towards a U-shape model, which we assume also for the other variants. In this context, it seems likely that the smallest fibril unit is not significantly impaired by the register-shift mutations at $\mathrm{Phe}_{19}$ or $\mathrm{Leu}_{34}$ and the $\mathrm{N}$-methylation at $\mathrm{Leu}_{34}$.

Regardless of the individual backbone modifications, parallel hydrogen-bonded $\beta$-strands are formed along the fibrillation axis $(4.8 \AA)$ verified by X-ray diffraction measurements ${ }^{33}$. Interestingly, when in general a mutation is introduced at $\mathrm{Leu}_{34}$ the inter- $\beta$-sheet distance (around the distinct reflection for $4.8 \AA$ ) is more diffuse compared to $\mathbf{W T}, \mathbf{F}+\mathbf{1}$ and $\mathbf{F}+\mathbf{2}$. This implies that the $3 \mathrm{D}$ space, required by the side chain of $\mathrm{Leu}_{34}$, introduces more structural inhomogeneity during packing along the fibrillation axis in the mutants, than the planar phenyl ring does. This is also true for the $\mathrm{N}$-methylated variant meaning that the extended backbone modification and the $N$-methylation are in terms of local packing density/arrangement more similar than initially expected. This hypothesis is supported by the findings from ${ }^{13} \mathrm{C}-{ }^{13} \mathrm{C}$ DARR NMR experiments (NMR labeling scheme 2) on $\mathbf{L}+\mathbf{1}$, $N$-Me-L and WT, where the inter- $\beta$-strand contact between $\mathrm{Phe}_{19}$ and $\mathrm{Ile}_{32}$ could be found for both the mutants due to the same steric demand of the modification (see Fig. 7). All these observations lead to the interpretation that backbone extensions have more impact on $\mathrm{Leu}_{34}$, while $\mathrm{N}$-methylations do on $\mathrm{Phe}_{19}$.

\section{Conclusion}

In summary, in this study, a series of two types of $A \beta_{40}$ peptide backbone modification, namely incorporation of (i) a methylene or ethylene spacer group and (ii) a $N$-methylation at the amide functional group, at the amino acids at positions 19 or 34 were investigated. This approach was designed to probe the response of the $A \beta_{40}$ system to the introduced backbone perturbations to identify key points in the free energy landscape of fibril formation. In all peptide variants that formed fibrils, both types of modification at either position 19 and 34 do not disturb the cross- $\beta$ structure and the hydrophobic zipper interdigitation of the side chains and their dynamic behavior in the $\beta$-sheet parts of the putative U-shaped fibrils. However, the modifications lead, in most of the cases, to alterations in fibril formation kinetics, higher local structural heterogeneity, and somewhat modified fibril morphology without generally impairing the fibril formation capacities of the peptides. Both backbone extensions provide additional degrees of freedom, allowing for a more efficient structure formation process as seen in faster fibrillation kinetics. In contrast, $N$-methylation significantly delays or even completely abolishes fibrillation of the $\mathrm{A} \beta_{40}$ variants. This concludes a series of systematic studies where the influence of local perturbations in the $\mathrm{A} \beta_{40}$ sequence were introduced. While most modifications only lead to moderate alterations in the fibril formation process and structure, inter-sheet hydrogen bond formation turns out to be the most important contribution to $\mathrm{A} \beta_{40}$ fibril formation. Even the lack of only one or two inter-strand hydrogen bonds can completely abolish fibril formation stressing its importance for $A \beta 40$ fibril formation. However, essentially all modifications introduced in the $A \beta_{40}$ sequence led to alterations in one way or another in biological activity profiles as concluded from toxicity assays. This hints towards a more pronounced impact of these modifications on the transient oligomeric states of the $\mathrm{A} \beta_{40}$ peptide variants.

\section{Methods}

Peptide synthesis. Standard Fmoc solid phase synthesis was used to produce the $A \beta_{40}$ peptides with the WT sequence DAEFRHDSGY EVHHQKLVFE AEDVGSNKGA IIGLMVGGVV and six variants with the extended backbone modifications, namely $\beta$-homo-Phe ${ }_{19}(\mathbf{F}+\mathbf{1}), \beta$-homo-Leu - $_{34}(\mathbf{L}+\mathbf{1}), \beta$-homo-Phe 19 / $\beta$ homo-Leu ${ }_{34}(\mathbf{F}+\mathbf{1} / \mathbf{F}+\mathbf{1}), \quad \gamma-\mathrm{Phe}_{19}(\mathbf{F}+\mathbf{2}), \gamma-\mathrm{Leu}_{34}(\mathbf{L}+\mathbf{2}), \gamma-\mathrm{Phe}_{19} / \gamma-\mathrm{Leu}_{34}(\mathbf{F}+\mathbf{2} / \mathbf{L}+\mathbf{2})$ and three mutants with $\mathrm{N}$-methylated amide groups, namely $\mathrm{N}$-Me-Phe ${ }_{19}(\mathrm{~N}-\mathrm{Me}-\mathrm{F}), \mathrm{N}-\mathrm{Me}_{-} \mathrm{Leu}_{34}(\mathrm{~N}-\mathrm{Me}-\mathrm{L}), \mathrm{N}-\mathrm{Me}-\mathrm{Phe}{ }_{19} / \mathrm{N}-\mathrm{Me}^{-\mathrm{Leu}_{34}}$ $(\mathrm{N}-\mathrm{Me}-\mathrm{F} / \mathrm{N}-\mathrm{Me}-\mathrm{L})$ (the mutated residues are highlighted in bold in the peptide sequence). For NMR measurements, uniform ${ }^{13} \mathrm{C} /{ }^{15} \mathrm{~N}$ labeled amino acids were introduced at positions $\mathrm{Val}_{18}, \mathrm{Phe}_{20}, \mathrm{Ala}_{21}$, and $\mathrm{Gly}_{33}$ (labeling scheme 1) or $\mathrm{Phe}_{19}, \mathrm{Ala}_{21}, \mathrm{Ile}_{32}, \mathrm{Val}_{36}$ (labeling scheme 2) (underlined in the peptide sequence). Peptide synthesis was performed by the Peptide Synthesis Core Unit of Leipzig University (https://home.uni-leipzig.de/izkf/index peptide.html). The peptide purity level determined by HPLC analysis and MALDI mass spectrometry was $\geq 97 \%$ depending on the peptide (see supporting information).

$A \boldsymbol{\beta}_{40}$ fibril preparation. Peptide powder was dissolved in dimethyl sulfoxide (DMSO) (ca. 8.3-8.6 mg peptide in $80 \mu \mathrm{L}$ DMSO), incubated at room temperature for ca. $30 \mathrm{~min}$ and then diluted with aqueous buffer ( $25 \mathrm{mM}$ sodium phosphate, $150 \mathrm{mM} \mathrm{NaCl}, 0.01 \%(\mathrm{w} / \mathrm{v}) \mathrm{NaN}_{3}, \mathrm{pH} 7.4$ ) at a concentration of $1 \mathrm{mg} \mathrm{mL}^{-1}$. For fibrillation, the sample was transferred into $1.5 \mathrm{~mL}$ reaction tubes and incubated for 14 days at $37^{\circ} \mathrm{C}$ and $450 \mathrm{rpm}$ in a thermoshaker. Fibrils prepared by this procedure were used for X-ray diffraction and NMR measurements. For transmission electron microscopy measurements, fibrils were taken out of the 96-well plate from thioflavin $\mathrm{T}(\mathrm{ThT})$ fluorescence fibrillation assay after completion of the fibrillation process.

Data representation. Experimental data derived from thioflavin T (ThT) fluorescence, transmission electron microscopy (TEM) and toxicological assays and stainings are summarized in box plot representations. The box marks the interquartile range (IQR) delimiting $50 \%$ of the data; the empty square is the mean, while the notch represents the $95 \%$ confidence interval (CI) of the median; the whiskers show 1.5 times IQR (not the standard deviation) demarcating statistical outliers and crosses indicate $1 \%$ or $99 \%$ of the data, respectively. Significances were tested applying a heteroscedastic Student's t-Test using two-tailed distributions, ${ }^{*} \mathrm{p} \leq 0.05 ;{ }^{* *} \mathrm{p} \leq$ $0.01{ }^{* * *} \mathrm{p} \leq 0.001$ vs control; \# vs WT. 
Thioflavin T (ThT) fluorescence measurements. Peptide powder was dissolved in dimethyl sulfoxide (DMSO) (ca. 0.5-0.8 mg peptide in $10 \mu \mathrm{L} \mathrm{DMSO}$ ), incubated at room temperature for ca. $30 \mathrm{~min}$ and diluted at a concentration of $0.125 \mathrm{mg} \mathrm{mL}^{-1}$ (in two steps: first $1 \mathrm{mg} \mathrm{mL}^{-1}$, then $0.125 \mathrm{mg} \mathrm{mL}^{-1}$ ) with aqueous buffer ( $25 \mathrm{mM}$ sodium phosphate, $150 \mathrm{mM} \mathrm{NaCl}, 0.01 \%(\mathrm{w} / \mathrm{v}) \mathrm{NaN}_{3}, \mathrm{pH}$ 7.4) containing $20 \mu \mathrm{MThT}$ ( $26.7 \mu \mathrm{LL}^{-1}$ of a $0.75 \mathrm{mM}$ ThT stock solution in $\mathrm{ddH}_{2} \mathrm{O}$ ). Three times, $125 \mu \mathrm{L}$ of this solution was transferred into a 96-well plate (Corning 96 -well half-area microplate, polystyrene with nonbinding surface coating, black, flat bottom clear). The dead time between preparation of the measuring solution and first measurement was $<5$ min. Triplicates of WT and mutant $\mathrm{A} \beta_{40}$ peptides were measured. ThT fluorescence was measured with a microplate reader (Tecan Infinite M200, Tecan Group AG, Mannedorf, Switzerland) at $37^{\circ} \mathrm{C}, 440 \mathrm{~nm}$ excitation wavelength, $482 \mathrm{~nm}$ emission detection, and shaking $/ 5 \mathrm{~min}$ waiting cycle. Measurements were performed every $5 \mathrm{~min}$ for $48 \mathrm{~h}$ or every $30 \mathrm{~min}$ for $192 \mathrm{~h}(\mathrm{~N}-\mathrm{Me}-\mathrm{L})$.

Crystal violet (CV) fluorescence measurements. Same procedure as for CV fluorescence measurements but using $5 \mu \mathrm{M} \mathrm{CV}\left(6.68 \mu \mathrm{L} \mathrm{mL}^{-1}\right.$ of a $0.75 \mathrm{mM}$ ThT stock solution in $\left.\mathrm{ddH}_{2} \mathrm{O}\right)$ and $584 \mathrm{~nm}$ excitation wavelength, as well as $620 \mathrm{~nm}$ emission detection instead. Triplicates of $\mathbf{W T}, F+1 / L+1$ and $F+2 / L+2$ were measured, but only qualitatively evaluated.

Fluorescence intensity data evaluation. Fluorescence intensity data were normalized by $I=\frac{\left(I_{t}-I_{\min }\right)}{I_{\max }}$ where $I$ is the normalized intensity, $I_{t}$ is the measured intensity value at the corresponding time point, and $I_{\min }$ and $I_{\max }$ are the minimal and maximal intensities measured for the corresponding well, respectively. Normalized data were fitted using a simple sigmoidal curve model ${ }^{75}, I=y_{i}+\frac{y_{f}}{1+e^{-\frac{\left(t-t_{0}\right)}{\tau}}}$, for the ThT fluorescence intensities, where $I$ is the normalized intensity, $t$ is the time, $t_{0}$ is the time at half maximal intensity, and $\tau$ is a measure for the fibrillation time. The lag time was derived by $t_{\mathrm{lag}}=t_{0}-2 \tau$ and the fibrillation time by $t_{\mathrm{fib}}=4 \tau$. Reported mean values and standard deviations were calculated from the different fit values. Values discussed in the text for fibril formation kinetics are given as mean \pm one standard deviation.

Transmission electron microscopy (TEM). A volume of $2 \mu \mathrm{L}$ of a diluted fibril solution from the final state of ThT measurements $\left(1: 20(\mathrm{v} / \mathrm{v})\right.$ with $\left.\mathrm{ddH}_{2} \mathrm{O}\right)$ was transferred onto a formvar film-coated copper grid. After evaporation of the solvent, the sample was stained with $1 \%$ uranyl acetate. Images were recorded on an electron microscope (Zeiss SIGMA) equipped with a STEM detector and operated with Atlas software (Zeiss NTS, Oberkochen, Germany). The diameters of the fibrils were measured $(n=100)$ with the free of charge program ImageJ $1.53 \mathrm{e}^{76}$. Values discussed in the text for fibril diameters are given as mean \pm one standard deviation.

X-ray diffraction measurements. Mature fibrils from solid-state NMR samples were taken out of the MAS rotor after measurement. Oil was used to stick the powdered/crystalline samples to nylon loops which were mounted on a Rigaku XtaLAB Synergy Custom X-ray crystallography system (Rigaku, Tokyo, Japan) equipped with a copper MicroMax-007 HF microfocus rotating anode source $\left(\mathrm{Cu} \mathrm{K} \mathrm{K}_{\alpha}\right.$ radiation) and a Hybrid Photon Counting (HPC) X-ray detector (HyPix-Arc $150^{\circ}$ ). Diffraction images were recorded with $120 \mathrm{~s}$ exposure time at room temperature $\left(+18{ }^{\circ} \mathrm{C}\right)$. The collected data was analyzed with the powder diffraction tool of the CrysAlis Pro software package. Inter- $\beta$-strand and inter- $\beta$-sheet distances were calculated using Bragg's law $(\lambda=1.5406 \AA): d=\frac{n \cdot \lambda}{2 \cdot \sin \theta}$.

Solid-state NMR measurements. After fibrillation, the peptide solution was centrifuged at $63,000 \times g$ for $2 \mathrm{~h}$ at $4{ }^{\circ} \mathrm{C}$. After removal of the supernatant, the pellets were frozen in liquid nitrogen and lyophilized for $72 \mathrm{~h}$ using a VaCo 2 lyophilizer (Zirbus technology GmbH, Bad Grund, Germany). For NMR measurements, the fibril pellets were rehydrated to $50 \%(\mathrm{w} / \mathrm{w}) \mathrm{dd}_{2} \mathrm{O}$. For homogenization, at least 10 freeze/thaw cycles were applied (liquid nitrogen $-37^{\circ} \mathrm{C}$ water bath/centrifugation at $16,000 \times g$ for $3 \mathrm{~s}$ ) and the sample was transferred into $3.2 \mathrm{~mm}$ MAS rotors. Solid-state MAS NMR spectra were recorded on a $600 \mathrm{MHz}$ Avance III NMR spectrometer (Bruker BioSpin GmbH, Rheinstetten, Germany) operated at resonance frequencies of 600.1, 150.9, and $60.8 \mathrm{MHz}$ for ${ }^{1} \mathrm{H},{ }^{13} \mathrm{C}$, and ${ }^{15} \mathrm{~N}$, respectively. Chemical shifts were given for ${ }^{13} \mathrm{C}$ relative to tetramethylsilane (TMS) and for ${ }^{15} \mathrm{~N}$ relative to liquid $\mathrm{NH}_{3}$. A triple channel $3.2 \mathrm{~mm}$ MAS probe operated at a temperature of $30{ }^{\circ} \mathrm{C}$ was used for all experiments. The $90^{\circ}$ pulse length was set to $4 \mu \mathrm{s}$ for ${ }^{1} \mathrm{H}$ in ${ }^{13} \mathrm{C}$ or ${ }^{15} \mathrm{~N}$ experiments. For cross-polarization (CP), a contact time of $1 \mathrm{~ms}$ and a spin lock field of ca. $50 \mathrm{kHz}$ were used. Relaxation delay was set to $2.5 \mathrm{~s}$ and the Spinal64 (small phase incremental alternation with 64 steps) sequence with a radio frequency (rf) amplitude of $62.5 \mathrm{kHz}$ was applied for ${ }^{1} \mathrm{H}$ decoupling. Two-dimensional NMR spectra were recorded using either a dual acquisition pulse sequence ${ }^{78}$, where one ${ }^{13} \mathrm{C}_{-13} \mathrm{CDARR}^{79}$ and four to eight ${ }^{15} \mathrm{~N}-{ }^{13} \mathrm{Ca}$ correlation spectra were acquired simultaneously, or a single ${ }^{13} \mathrm{C}-{ }^{13} \mathrm{C}$ DARR experiment. The mixing time for the DARR experiments was $500 \mathrm{~ms}$ (labeling scheme 1), 50 or $600 \mathrm{~ms}$ (labeling scheme 2), MAS frequency was set to $11,777 \mathrm{~Hz}$, and double $\mathrm{CP}$ contact times were $1 \mathrm{~ms}$ for ${ }^{1} \mathrm{H}-{ }^{15} \mathrm{~N}$ and $4 \mathrm{~ms}$ for ${ }^{13} \mathrm{C}-{ }^{15} \mathrm{~N}$ transfer steps. To determine the motional averaged ${ }^{1} \mathrm{H}^{13} \mathrm{C}$ dipolar couplings, constant time DipShift experiments with $5 \mathrm{kHz}$ MAS frequency and ca. $80 \mathrm{kHz}$ effective radio frequency field frequency switched Lee-Goldburg homonuclear decoupling ${ }^{80}$ were performed ${ }^{81}$. Using numerical simulation of the experimental dephasing curves over one rotor period, motional averaged dipolar couplings were determined. For DipShift time domain data simulation a C++ program was used. Euler angles for powder averaging were incremented in $1^{\circ}$ steps in the simulations. The best fit of the dephasing curve to the experimental data was used to determine motional averaged dipolar coupling values $\left\langle\delta_{\mathrm{CH}}\right\rangle$, from which the order parameters $S_{\mathrm{CH}}$ were calculated according to $S_{\mathrm{CH}}=\left\langle\delta_{\mathrm{CH}}\right\rangle / \delta_{\mathrm{CH}}$, where $\delta_{\mathrm{CH}}$ is the dipolar coupling rigid limit value derived frozen amino acid samples ${ }^{82,83}$. 
Cell culture. Primary neuronal cultures were established from fetal mouse brains of C57Bl/6 mice at gestation day 16 and grown under standard conditions ${ }^{84,85}$. Briefly, fetal brains were prepared, and neurons were dissociated into single cells by triturating the brains by means of pipets and passing the cell suspensions through sterile nylon meshes $(150 \mu \mathrm{m}$ and $20 \mu \mathrm{m})$. Suspensions were then grown in seeding medium (DMEM/Ham's F-12 supplemented with $5 \%(\mathrm{v} / \mathrm{v})$ fetal horse serum (FHS) and $1 \%(\mathrm{v} / \mathrm{v})$ penicillin-streptomycin-neomycin (PSN) antibiotic mixture) in 96-well culture plates (for MTT and LDH assays) or on poly-L-lysine-coated glass coverslips in 24-well culture plates (for immunocytochemistry), respectively. The cells were cultured at $37^{\circ} \mathrm{C}$ in a humidified atmosphere containing $5 \%(\mathrm{v} / \mathrm{v}) \mathrm{CO}_{2}$. On the following day, the seeding medium was exchanged by neuronal medium (Dulbecco's Modified Eagle Medium/Nutrient Mixture F-12 (DMEM/Ham's F-12) supplemented with $1 \%(\mathrm{v} / \mathrm{v})$ PSN, $1 \%(\mathrm{v} / \mathrm{v}) \mathrm{N}-2$ supplement and $20 \%(\mathrm{v} / \mathrm{v})$ astrocyte conditioned medium). After 3 days in vitro, cultures were stimulated with $\mathrm{A} \beta_{40}$ peptides at concentrations of $10 \mu \mathrm{M}$ for $18 \mathrm{~h}$.

Neuronal survival was analyzed using the 3-(4,5-dimethylthiazol-2-yl)-2,5-diphenyltetrazolium bromide (MTT) assay which measures glycolytic activity. Briefly, MTT was dissolved in cell culture media without serum and added to the primary neurons for $2 \mathrm{~h}$. After addition of dimethyl sulfoxide (DMSO)/EtOH $(1: 1, \mathrm{v} / \mathrm{v})$ and shaking for $10 \mathrm{~min}$, the absorbance was measured at $592 \mathrm{~nm}$ (Mithras LB 940, Berthold Technologies).

Neuronal cell death was measured in cell culture supernatant by lactate dehydrogenase (LDH) assay (Promega, CytoTox96) according to the manufacturer's protocol. $\mathrm{LDH}$ is a cytosolic protein, which is not detectable extracellularly under normal conditions, but only in the case of membrane leakage.

Immunocytochemistry. Cells grown on coverslips were stained with primary antibodies against activated caspase-3 (1:100, AF835, R\&D Systems) and neurofilament M and H (1:1000, 171,104, 171,204, Synaptic Systems) in Tris-buffered saline (TBS) (0.1 M, pH 7.4) containing $0.1 \%(\mathrm{v} / \mathrm{v})$ Triton X-100 and 5\% (v/v) normal donkey serum at $4{ }^{\circ} \mathrm{C}$ overnight. On the next day, coverslips were washed thrice with TBS and then incubated with the respective secondary antibodies donkey anti-rabbit-Cy3 (1:400 (v/v), 711-225-152, Dianova), donkey anti-guinea pig-Cy2 (1:400 (v/v), Dianova) in TBS containing 2\% (v/v) bovine serum albumin (BSA, Serva Electrophoresis $\mathrm{GmbH}$ ) for $60 \mathrm{~min}$ at room temperature. After rinsing with TBS, cell nuclei were stained with Hoechst 33342 in TBS (1:10,000 (v/v)) for $10 \mathrm{~min}$ at room temperature. The coverslips were washed, air-dried, embedded with Entellan /toluene on glass slides, and stored at $4^{\circ} \mathrm{C}$ in the dark.

Stained coverslips were examined with an AxioScan.Z1 microscope (Carl Zeiss, Göttingen, Germany). Emission filters were selected for Cy2 $(524 \mathrm{~nm})$, for Cy3 $(595 \mathrm{~nm})$ and Hoechst $33342(425 \mathrm{~nm})$. Images were taken by means of Axiocam 506 and a Plan-Apochromat objective $(20 \times / 0.8)$ and digitized using ZEN 3.4 software. For quantification of neurite lengths, regions of interest were digitized by means of Keyence microscope BZ9000 and lengths were measured using BZ II Analyzer 2.1 software.

Control experiments were performed by omitting the primary antibody. All controls were negative, indicating that the observed fluorescence signals were specific. For quantification, ten regions of interest from each coverslip were randomly selected and mean intensity values of activated caspase- 3 and Hoechst 33342 signals were determined.

Received: 2 August 2021; Accepted: 25 November 2021

Published online: 09 December 2021

\section{References}

1. Bartolotti, N. \& Lazarov, O. Lifestyle and Alzheimer's disease. In Genes, Environment and Alzheimer's Disease (eds Lazarov, O. \& Tesco, G.) 197-237 (Academic Press, 2016).

2. Doig, A. J. et al. Why is research on amyloid- $\beta$ failing to give new drugs for Alzheimer's disease?. ACS Chem. Neurosci. 8, $1435-1437$. https://doi.org/10.1021/acschemneuro.7b00188 (2017).

3. Busche, M. A. \& Hyman, B. T. Synergy between amyloid- $\beta$ and tau in Alzheimer's disease. Nat. Neurosci. 23, 1183-1193. https:// doi.org/10.1038/s41593-020-0687-6 (2020).

4. Gallardo, R., Ranson, N. A. \& Radford, S. E. Amyloid structures: Much more than just a cross- $\beta$ fold. Curr. Opin. Struct. Biol. 60, 7-16. https://doi.org/10.1016/j.sbi.2019.09.001 (2020).

5. Lotz, G. P. \& Legleiter, J. The role of amyloidogenic protein oligomerization in neurodegenerative disease. J. Mol. Med. 91, 653-664. https://doi.org/10.1007/s00109-013-1025-1 (2013).

6. Jahn, T. R. \& Radford, S. E. The Yin and Yang of protein folding. FEBS J. 272, 5962-5970. https://doi.org/10.1111/j.1742-4658. 2005.05021.x (2005).

7. Tolar, M., Hey, J., Power, A. \& Abushakra, S. Neurotoxic soluble amyloid oligomers drive Alzheimer's pathogenesis and represent a clinically validated target for slowing disease progression. Int. J. Mol. Sci. 22, 6355. https://doi.org/10.3390/ijms22126355 (2021).

8. Kayed, R. \& Lasagna-Reeves, C. A. Molecular mechanisms of amyloid oligomers toxicity. J. Alzheimers Dis. 33(Suppl 1), S67-78. https://doi.org/10.3233/JAD-2012-129001 (2013).

9. Hampel, H. et al. The amyloid- $\beta$ pathway in Alzheimer's disease. Mol. Psychiatry. https://doi.org/10.1038/s41380-021-01249-0 (2021).

10. Lendel, C. et al. A hexameric peptide barrel as building block of amyloid- $\beta$ protofibrils. Angew. Chem. Int. Ed. Engl. 53, 1275612760. https://doi.org/10.1002/anie.201406357 (2014).

11. Ciudad, S. et al. A $\beta(1-42)$ tetramer and octamer structures reveal edge conductivity pores as a mechanism for membrane damage. Nat. Commun. 11, 3014. https://doi.org/10.1038/s41467-020-16566-1 (2020).

12. Scheidt, H. A., Morgado, I., Rothemund, S., Huster, D. \& Fändrich, M. Solid-state NMR spectroscopic investigation of A $\beta$ protofibrils: Implication of a $\beta$-sheet remodeling upon maturation into terminal amyloid fibrils. Angew. Chem. Int. Ed. Engl. 50, $2837-2840$. https://doi.org/10.1002/anie.201007265 (2011).

13. Petkova, A. T. et al. A structural model for Alzheimer's beta -amyloid fibrils based on experimental constraints from solid state NMR. Proc. Natl. Acad. Sci. USA 99, 16742-16747. https://doi.org/10.1073/pnas.262663499 (2002).

14. Fitzpatrick, A. W. P. et al. Atomic structure and hierarchical assembly of a cross- $\beta$ amyloid fibril. Proc. Natl. Acad. Sci. USA 110, 5468-5473. https://doi.org/10.1073/pnas.1219476110 (2013). 
15. Bertini, I., Gonnelli, L., Luchinat, C., Mao, J. \& Nesi, A. A new structural model of A $\beta 40$ fibrils. J. Am. Chem. Soc. 133, 16013-16022. https://doi.org/10.1021/ja2035859 (2011).

16. Qiang, W., Yau, W.-M., Luo, Y., Mattson, M. P. \& Tycko, R. Antiparallel $\beta$-sheet architecture in Iowa-mutant $\beta$-amyloid fibrils. Proc. Natl. Acad. Sci. USA 109, 4443-4448. https://doi.org/10.1073/pnas.1111305109 (2012).

17. Gremer, L. et al. Fibril structure of amyloid- $\beta(1-42)$ by cryo-electron microscopy. Science 358, 116-119. https://doi.org/10.1126/ science.aao2825 (2017).

18. Chiti, F. \& Dobson, C. M. Protein misfolding, amyloid formation, and human disease: A summary of progress over the last decade. Annu. Rev. Biochem. 86, 27-68. https://doi.org/10.1146/annurev-biochem-061516-045115 (2017).

19. Dobson, C. M. Protein folding and misfolding. Nature 426, 884-890. https://doi.org/10.1038/nature02261 (2003).

20. Wetzel, R. Kinetics and thermodynamics of amyloid fibril assembly. Acc. Chem. Res. 39, 671-679. https://doi.org/10.1021/ar050 069h (2006).

21. Mao, Y. et al. Hydrogen/deuterium exchange and molecular dynamics analysis of amyloid fibrils formed by a D69K charge-pair mutant of human apolipoprotein C-II. Biochemistry 54, 4805-4814. https://doi.org/10.1021/acs.biochem.5b00535 (2015).

22. Mao, Y. et al. Charge and charge-pair mutations alter the rate of assembly and structural properties of apolipoprotein C-II amyloid fibrils. Biochemistry 54, 1421-1428. https://doi.org/10.1021/bi5014535 (2015).

23. Vignaud, H. et al. A structure-toxicity study of Aß42 reveals a new anti-parallel aggregation pathway. PLoS ONE 8, e80262. https:// doi.org/10.1371/journal.pone.0080262 (2013).

24. Hoffmann, F. et al. Perturbation of the F19-L34 contact in amyloid $\beta$ (1-40) fibrils induces only local structural changes but abolishes cytotoxicity. J. Phys. Chem. Lett. 8, 4740-4745. https://doi.org/10.1021/acs.jpclett.7b02317 (2017).

25. Adler, J., Scheidt, H. A., Krüger, M., Thomas, L. \& Huster, D. Local interactions influence the fibrillation kinetics, structure and dynamics of $A \beta(1-40)$ but leave the general fibril structure unchanged. Phys. Chem. Chem. Phys. 16, 7461-7471. https://doi.org/ $10.1039 / \mathrm{c} 3 \operatorname{cp} 54501 \mathrm{f}(2014)$.

26. Adler, J. et al. A detailed analysis of the morphology of fibrils of selectively mutated amyloid $\beta(1-40)$. ChemPhysChem 17, 2744-2753. https://doi.org/10.1002/cphc.201600413 (2016).

27. Das, A. K. et al. An early folding contact between Phe19 and Leu34 is critical for amyloid- $\beta$ oligomer toxicity. ACS Chem. Neurosci. 6, 1290-1295. https://doi.org/10.1021/acschemneuro.5b00074 (2015).

28. Tycko, R. Molecular structure of aggregated amyloid- $\beta$ : Insights from solid-state nuclear magnetic resonance. Cold Spring Harb. Perspect. Med. 6, a024083. https://doi.org/10.1101/cshperspect.a024083 (2016).

29. Sciarretta, K. L., Boire, A., Gordon, D. J. \& Meredith, S. C. Spatial separation of beta-sheet domains of beta-amyloid: Disruption of each beta-sheet by N-methyl amino acids. Biochemistry 45, 9485-9495. https://doi.org/10.1021/bi0605585 (2006).

30. Gordon, D. J., Tappe, R. \& Meredith, S. C. Design and characterization of a membrane permeable N-methyl amino acid-containing peptide that inhibits Abeta1-40 fibrillogenesis. J. Peptide Res. 60, 37-55. https://doi.org/10.1034/j.1399-3011.2002.11002.x (2002).

31. Gordon, D. J., Sciarretta, K. L. \& Meredith, S. C. Inhibition of beta-amyloid(40) fibrillogenesis and disassembly of beta-amyloid(40) fibrils by short beta-amyloid congeners containing N-methyl amino acids at alternate residues. Biochemistry 40, 8237-8245. https:// doi.org/10.1021/bi002416v (2001).

32. Kajava, A. V., Baxa, U. \& Steven, A. C. Beta arcades: Recurring motifs in naturally occurring and disease-related amyloid fibrils. FASEB J. 24, 1311-1319. https://doi.org/10.1096/fi.09-145979 (2010).

33. Eisenberg, D. \& Jucker, M. The amyloid state of proteins in human diseases. Cell 148, 1188-1203. https://doi.org/10.1016/j.cell. 2012.02.022 (2012).

34. Tycko, R. Solid-state NMR studies of amyloid fibril structure. Annu. Rev. Phys. Chem. 62, 279-299. https://doi.org/10.1146/annur ev-physchem-032210-103539 (2011).

35. Biancalana, M. \& Koide, S. Molecular mechanism of thioflavin-T binding to amyloid fibrils. Biochim. Biophys. Acta 1405-1412, 2010. https://doi.org/10.1016/j.bbapap.2010.04.001 (1804).

36. Hasecke, F. et al. Origin of metastable oligomers and their effects on amyloid fibril self-assembly. Chem. Sci. 9, 5937-5948. https:// doi.org/10.1039/c8sc01479e (2018).

37. Barton, J. et al. Kinetic transition in amyloid assembly as a screening assay for oligomer-selective dyes. Biomolecules 9, 539-554. https://doi.org/10.3390/biom9100539 (2019).

38. Cruz, M. et al. Inhibition of beta-amyloid toxicity by short peptides containing N-methyl amino acids. J. Peptide Res. 63, 324-328. https://doi.org/10.1111/j.1399-3011.2004.00156.x (2004).

39. Hughes, E., Burke, R. M. \& Doig, A. J. Inhibition of toxicity in the beta-amyloid peptide fragment beta-(25-35) using N-methylated derivatives: A general strategy to prevent amyloid formation. J. Biol. Chem. 275, 25109-25115. https://doi.org/10.1074/jbc.M0035 54200 (2000).

40. Chatterjee, J., Gilon, C., Hoffman, A. \& Kessler, H. N-methylation of peptides: A new perspective in medicinal chemistry. Acc. Chem. Res. 41, 1331-1342. https://doi.org/10.1021/ar8000603 (2008).

41. Yan, L.-M. et al. Selectively N-methylated soluble IAPP mimics as potent IAPP receptor agonists and nanomolar inhibitors of cytotoxic self-assembly of both IAPP and A $\beta 40$. Angew. Chem. Int. Ed. Engl. 52, 10378-10383. https://doi.org/10.1002/anie.20130 2840 (2013).

42. Morris, K. L. \& Serpell, L. C. X-ray fibre diffraction studies of amyloid fibrils. In Amyloid Proteins Methods and Protocols 2nd edn, Vol. 849 (eds Sigurdsson, E. M. et al.) 121-135 (Humana Press, 2012).

43. Sunde, M. et al. Common core structure of amyloid fibrils by synchrotron X-ray diffraction. J. Mol. Biol. 273, 729-739. https:// doi.org/10.1006/jmbi.1997.1348 (1997).

44. Henry, G. D. \& Sykes, B. D. [18] Methods to study membrane protein structure in solution. Methods Enzymol. 239, 515-535 (1994).

45. Meinhardt, J., Sachse, C., Hortschansky, P., Grigorieff, N. \& Fändrich, M. Abeta(1-40) fibril polymorphism implies diverse interaction patterns in amyloid fibrils. J. Mol. Biol. 386, 869-877. https://doi.org/10.1016/j.jmb.2008.11.005 (2009).

46. Petkova, A. T. et al. Self-propagating, molecular-level polymorphism in Alzheimer's beta-amyloid fibrils. Science 307, $262-265$. https://doi.org/10.1126/science.1105850 (2005).

47. Tycko, R. Amyloid polymorphism: Structural basis and neurobiological relevance. Neuron 86, 632-645. https://doi.org/10.1016/j. neuron.2015.03.017 (2015).

48. Close, W. et al. Physical basis of amyloid fibril polymorphism. Nat. Commun. 9, 699-706. https://doi.org/10.1038/s41467-01803164-5 (2018).

49. Tycko, R. Physical and structural basis for polymorphism in amyloid fibrils. Protein Sci. 23, 1528-1539. https://doi.org/10.1002/ pro.2544 (2014).

50. Munowitz, M. G., Griffin, R. G., Bodenhausen, G. \& Huang, T. H. Two-dimensional rotational spin-echo nuclear magnetic resonance in solids: Correlation of chemical shift and dipolar interactions. J. Am. Chem. Soc. 103, 2529-2533. https://doi.org/10.1021/ ja00400a007 (1981).

51. Sackewitz, M. et al. Structural and dynamical characterization of fibrils from a disease-associated alanine expansion domain using proteolysis and solid-state NMR spectroscopy. J. Am. Chem. Soc. 130, 7172-7173. https://doi.org/10.1021/ja800120s (2008).

52. Selkoe, D. J. Folding proteins in fatal ways. Nature 426, 900-904. https://doi.org/10.1038/nature02264 (2003).

53. Eichner, T. \& Radford, S. E. A diversity of assembly mechanisms of a generic amyloid fold. Mol. Cell 43, 8-18. https://doi.org/10. 1016/j.molcel.2011.05.012 (2011). 
54. Almeida, Z. L. \& Brito, R. M. M. Structure and aggregation mechanisms in amyloids. Molecules 25, 1195. https://doi.org/10.3390/ molecules25051195 (2020).

55. Adamcik, J. \& Mezzenga, R. Amyloid polymorphism in the protein folding and aggregation energy landscape. Angew. Chem. Int. Ed. Engl. 57, 8370-8382. https://doi.org/10.1002/anie.201713416 (2018).

56. Zheng, W., Tsai, M.-Y., Chen, M. \& Wolynes, P. G. Exploring the aggregation free energy landscape of the amyloid- $\beta$ protein (1-40). Proc. Natl. Acad. Sci. USA 113, 11835-11840. https://doi.org/10.1073/pnas.1612362113 (2016).

57. Korn, A., Surendran, D., Krueger, M., Maiti, S. \& Huster, D. Ring structure modifications of phenylalanine 19 increase fibrillation kinetics and reduce toxicity of amyloid $\beta$ (1-40). Chem. Commun. 54, 5430-5433. https://doi.org/10.1039/c8cc01733f (2018).

58. Korn, A. et al. Amyloid $\beta$ (1-40) toxicity depends on the molecular contact between phenylalanine 19 and leucine 34. ACS Chem. Neurosci. 9, 790-799. https://doi.org/10.1021/acschemneuro.7b00360 (2018).

59. Korn, A. et al. Incorporation of the nonproteinogenic amino acid $\beta$-methylamino-alanine affects amyloid $\beta$ fibril properties and toxicity. ACS Chem. Neurosci. 11, 1038-1047. https://doi.org/10.1021/acschemneuro.9b00660 (2020).

60. Nelson, R. et al. Structure of the cross-beta spine of amyloid-like fibrils. Nature 435, 773-778. https://doi.org/10.1038/nature03680 (2005)

61. Jarrett, J. T. \& Lansbury, P. T. Seeding, “one-dimensional crystallization” of amyloid: A pathogenic mechanism in Alzheimer's disease and scrapie?. Cell 73, 1055-1058. https://doi.org/10.1016/0092-8674(93)90635-4 (1993).

62. Sciacca, M. F. M. et al. Two-step mechanism of membrane disruption by A $\beta$ through membrane fragmentation and pore formation. Biophys. J. 103, 702-710. https://doi.org/10.1016/j.bpj.2012.06.045 (2012).

63. Sciacca, M. F. M., Brender, J. R., Lee, D. \& Ramamoorthy, A. Phosphatidylethanolamine enhances amyloid fiber-dependent membrane fragmentation. Biochemistry 51, 7676-7684. https://doi.org/10.1021/bi3009888 (2012).

64. Lashuel, H. A. \& Lansbury, P. T. Are amyloid diseases caused by protein aggregates that mimic bacterial pore-forming toxins?. Q. Rev. Biophys. 39, 167-201. https://doi.org/10.1017/S0033583506004422 (2006).

65. Scollo, F. \& La Rosa, C. Amyloidogenic intrinsically disordered proteins: New insights into their self-assembly and their interaction with membranes. Life 10, 144-164. https://doi.org/10.3390/life10080144 (2020).

66. Williams, T. L., Day, I. J. \& Serpell, L. C. The effect of Alzheimer's A $\beta$ aggregation state on the permeation of biomimetic lipid vesicles. Langmuir 26, 17260-17268. https://doi.org/10.1021/la101581g (2010).

67. Kokkoni, N., Stott, K., Amijee, H., Mason, J. M. \& Doig, A. J. N-Methylated peptide inhibitors of beta-amyloid aggregation and toxicity. Optimization of the inhibitor structure. Biochemistry 45, 9906-9918. https://doi.org/10.1021/bi060837s (2006).

68. Goyal, D., Shuaib, S., Mann, S. \& Goyal, B. Rationally designed peptides and peptidomimetics as inhibitors of amyloid- $\beta$ (A $\beta$ ) aggregation: Potential therapeutics of Alzheimer's disease. ACS Comb. Sci. 19, 55-80. https://doi.org/10.1021/acscombsci.6b001 16 (2017).

69. Sciarretta, K. L., Gordon, D. J. \& Meredith, S. C. Peptide-based inhibitors of amyloid assembly. In Amyloid, Prions, and Other Protein Aggregates Part C 1st edn, Vol. 413 (eds Kheterpal, I. \& Wetzel, R.) 273-312 (Elsevier/Academic, 2006).

70. Paul, A. et al. An explicitly designed paratope of amyloid- $\beta$ prevents neuronal apoptosis in vitro and hippocampal damage in rat brain. Chem. Sci. 12, 2853-2862. https://doi.org/10.1039/D0SC04379F (2021).

71. Kollmer, M. et al. Cryo-EM structure and polymorphism of $A \beta$ amyloid fibrils purified from Alzheimer's brain tissue. Nat. Commun. 10, 4760-4768. https://doi.org/10.1038/s41467-019-12683-8 (2019).

72. Ghosh, U., Thurber, K. R., Yau, W.-M. \& Tycko, R. Molecular structure of a prevalent amyloid- $\beta$ fibril polymorph from Alzheimer's disease brain tissue. Proc. Natl. Acad. Sci. USA https://doi.org/10.1073/pnas.2023089118 (2021).

73. Schütz, A. K. et al. Atomic-resolution three-dimensional structure of amyloid $\beta$ fibrils bearing the Osaka mutation. Angew. Chem. Int. Ed. Engl. 54, 331-335. https://doi.org/10.1002/anie.201408598 (2015).

74. Lu, J.-X. et al. Molecular structure of $\beta$-amyloid fibrils in Alzheimer's disease brain tissue. Cell 154, 1257-1268. https://doi.org/10. 1016/j.cell.2013.08.035 (2013).

75. Nielsen, L. et al. Effect of environmental factors on the kinetics of insulin fibril formation: Elucidation of the molecular mechanism. Biochemistry 40, 6036-6046. https://doi.org/10.1021/bi002555c (2001).

76. Abramoff, M. D., Magalhaes, P. J. \& Ram, S. J. Image processing with ImageJ. Biophoton. Int. 11, 36-42 (2004).

77. Fung, B. M., Khitrin, A. K. \& Ermolaev, K. An improved broadband decoupling sequence for liquid crystals and solids. J. Magn. Reson. 142, 97-101. https://doi.org/10.1006/jmre.1999.1896 (2000).

78. Gopinath, T. \& Veglia, G. Dual acquisition magic-angle spinning solid-state NMR-spectroscopy: Simultaneous acquisition of multidimensional spectra of biomacromolecules. Angew. Chem. Int. Ed. Engl. 51, 2731-2735. https://doi.org/10.1002/anie.20110 8132 (2012).

79. Takegoshi, K., Nakamura, S. \& Terao, T. 13C-1H dipolar-assisted rotational resonance in magic-angle spinning NMR. Chem. Phys. Lett. 344, 631-637. https://doi.org/10.1016/S0009-2614(01)00791-6 (2001).

80. Bielecki, A., Kolbert, A. C. \& Levitt, M. H. Frequency-switched pulse sequences: Homonuclear decoupling and dilute spin NMR in solids. Chem. Phys. Lett. 155, 341-346. https://doi.org/10.1016/0009-2614(89)87166-0 (1989).

81. Huster, D., Yamaguchi, S. \& Hong, M. Efficient $\beta$-sheet identification in proteins by solid-state NMR spectroscopy. J. Am. Chem. Soc. 122, 11320-11327. https://doi.org/10.1021/ja001674c (2000).

82. Barré, P., Zschörnig, O., Arnold, K. \& Huster, D. Structural and dynamical changes of the bindin B18 peptide upon binding to lipid membranes. A solid-state NMR study. Biochemistry 42, 8377-8386. https://doi.org/10.1021/bi034239e (2003).

83. Huster, D., Xiao, L. \& Hong, M. Solid-state NMR investigation of the dynamics of the soluble and membrane-bound colicin Ia channel-forming domain. Biochemistry 40, 7662-7674. https://doi.org/10.1021/bi0027231 (2001).

84. Hartlage-Rübsamen, M. et al. Isoglutaminyl cyclase contributes to CCL2-driven neuroinflammation in Alzheimer's disease. Acta Neuropathol. 129, 565-583. https://doi.org/10.1007/s00401-015-1395-2 (2015).

85. Heiland, T. et al. Defined astrocytic expression of human amyloid precursor protein in Tg2576 mouse brain. Glia 67, 393-403. https://doi.org/10.1002/glia.23550 (2019).

\section{Acknowledgements}

The authors acknowledge Dr. J. Adler for very helpful ideas and assistance throughout the whole project and Prof. H. Krautscheid and M. Sc. S. Henfling at Leipzig University and Prof. M. Stubbs and Dr. C. Parthier at MLU Halle for offering access to their X-ray diffraction facilities. Also, Dr. S. Rothemund at Peptide Synthesis Core Unit of Leipzig University is thanked for peptide synthesis. The study was supported by the DFG (TRRSFB 102, A06 and Z01).

\section{Author contributions}

D.H. conceived the research. B.S. prepared samples, carried out all physicochemical experiments and did the data analysis. M.K. did the TEM measurements, A.K. helped with some physicochemical experiments and data analysis. C.H., U.Z. and S.R. conducted toxicity assays. B.S. and D.H. wrote the manuscript with input from all other co-authors. All authors reviewed the manuscript. 


\section{Funding}

Open Access funding enabled and organized by Projekt DEAL.

\section{Competing interests}

The authors declare no competing interests.

\section{Additional information}

Supplementary Information The online version contains supplementary material available at https://doi.org/ 10.1038/s41598-021-03091-4.

Correspondence and requests for materials should be addressed to D.H.

Reprints and permissions information is available at www.nature.com/reprints.

Publisher's note Springer Nature remains neutral with regard to jurisdictional claims in published maps and institutional affiliations.

(c) (i) Open Access This article is licensed under a Creative Commons Attribution 4.0 International License, which permits use, sharing, adaptation, distribution and reproduction in any medium or format, as long as you give appropriate credit to the original author(s) and the source, provide a link to the Creative Commons licence, and indicate if changes were made. The images or other third party material in this article are included in the article's Creative Commons licence, unless indicated otherwise in a credit line to the material. If material is not included in the article's Creative Commons licence and your intended use is not permitted by statutory regulation or exceeds the permitted use, you will need to obtain permission directly from the copyright holder. To view a copy of this licence, visit http://creativecommons.org/licenses/by/4.0/.

(C) The Author(s) 2021 